University of Louisville

ThinkIR: The University of Louisville's Institutional Repository

Electronic Theses and Dissertations

$12-2012$

\title{
A model of resilience in children at risk for the development of anxiety.
}

Matthew David Hartman Schrock

University of Louisville

Follow this and additional works at: https://ir.library.louisville.edu/etd

\section{Recommended Citation}

Schrock, Matthew David Hartman, "A model of resilience in children at risk for the development of anxiety." (2012). Electronic Theses and Dissertations. Paper 1282.

https://doi.org/10.18297/etd/1282

This Doctoral Dissertation is brought to you for free and open access by ThinkIR: The University of Louisville's Institutional Repository. It has been accepted for inclusion in Electronic Theses and Dissertations by an authorized administrator of ThinkIR: The University of Louisville's Institutional Repository. This title appears here courtesy of the author, who has retained all other copyrights. For more information, please contact thinkir@louisville.edu. 


\title{
A MODEL OF RESILIENCE IN CHILDREN AT RISK FOR THE DEVELOPMENT OF ANXIETY
}

\author{
By
}

\author{
Matthew David Hartman Schrock \\ B.A., Eckerd College, 1998 \\ M.A., University of Louisville, 2009
}

A Dissertation Submitted to the Faculty of the College of Arts and Sciences of the University of Louisville in Partial Fulfillment of the Requirements for the Degree of

Doctor of Philosophy

Department of Psychological and Brain Sciences

University of Louisville

Louisville, KY

December 2012 
A MODEL OF RESILIENCE IN CHILDREN AT RISK FOR THE DEVELOPMENT OF ANXIETY

By

Matthew David Hartman Schrock
B.A., Eckerd College, 1998
M.A., University of Louisville, 2009

Dissertation Approved on:

October $26^{\text {th }}, 2012$

By the following Dissertation Committee:

Janet Woodruff-Borden, Ph.D., Dissertation Advisor

Cara Cashon, Ph.D.

Sarah Honaker, Ph.D.

Benjamin Mast, Ph.D.

Paul Salmon, Ph.D. 


\section{DEDICATION}

I would like to dedicate this project to my wife, Betsy, and my son, Dylan, who have sacrificed so much see me through my doctoral degree. Thank you for being an enduring source of strength, for surviving the long nights and weekends, and for encouraging me when I needed it most. 


\section{ACKNOWLEDGEMENTS}

Thank you to Dr. Janet Woodruff-Borden, a continual source of support and encouragement during my graduate training. I am tremendously grateful for her mentorship and the essential role she has played in my academic and professional development. I would also like to thank my committee members, Drs. Cara Cashon, Sarah Honaker, Ben Mast, and Paul Salmon for their valuable time and thoughtful consideration of this project. Thanks to my lab mates, Ryan Hosey, Sarah Kertz, and Sarah Williams, who provided invaluable input, insight, and friendship. Special thanks to my parents for their unconditional enthusiasm and sincere belief in my pursuits. Finally, countless thanks to all of the families who offered considerable time and energy to contribute to this project, and who have helped to advance our understanding of anxiety. 


\title{
ABSTRACT \\ A MODEL OF RESILIENCE IN CHILDREN AT RISK FOR THE DEVELOPMENT OF ANXIETY
}

Matthew Schrock

October $26^{\text {th }}, 2012$

\begin{abstract}
Anxiety is a common and debilitating disorder in children. Until recently, research in the field of child anxiety has focused on the identification of specific risk factors in the development of child anxiety. More recent studies have begun to explore more complex models of the etiology of child anxiety, but most still focus on the interplay of risk factors. Studies examining the development of child anxiety should focus on the confluence of vulnerability, risk, and protective factors to provide a more complete picture of the development of child anxiety. The current study reviews current conceptual and empirical research to propose a model of resilience in children at risk for the development of anxiety. In a first step in testing the proposed model, the current study examined the role of child emotion regulation as a mediator in the relationship between parent, child, and family factors and child anxiety. The study utilized a community sample of children ages $7-10$ years and their parents. The final study sample consisted of 100 parent-child dyads recruited across three geographic areas. The sample was comprised of primarily European American mothers and their children. The study tested several related hypotheses. First, to validate inclusion of study variables relationships between parent anxiety symptoms, child temperament, parenting behavior, family
\end{abstract}


environment, and marital relationship were examined. Next, to support the inclusion of these parent, child, and family variables in the test for mediation, the relationship between these variables and child emotion regulation and child anxiety was explored. Finally, the potential mediating role of child emotion regulation was explored. Additional exploratory analyses investigating specific subscales of the emotion regulation measures as mediators and potential differences in child emotion regulation in high and low anxious children were also considered. Results from the current study supported the inclusion of parent, child, and family factors in the proposed model, and confirmed the role of child emotion regulation as a mediator of the relationships between several of the variables and child anxiety. The mediation of child anxiety through child emotion regulation might represent a resilience process in children temperamentally at risk for developing anxiety. Results further substantiate the need to move from simple direct relationships to consideration of more complex transactional models in the etiology of child anxiety. The findings are discussed in terms of theoretical and clinical implications, strengths and weaknesses of the current study are presented, and suggestions for future research offered. 


\section{TABLE OF CONTENTS}

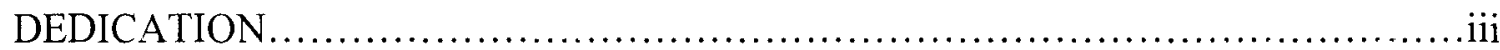

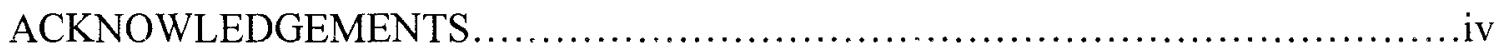

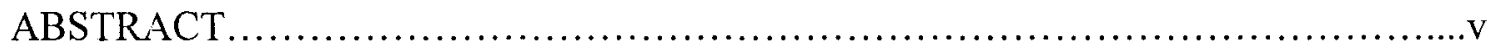

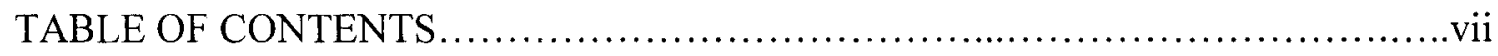

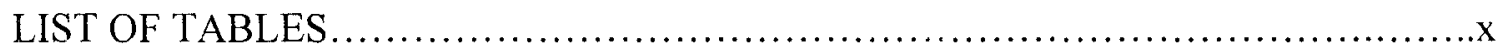

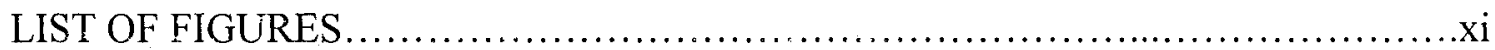

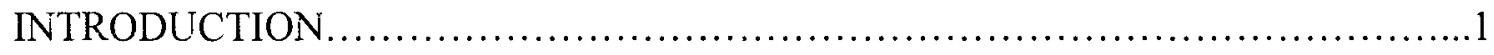

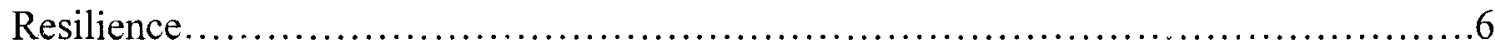

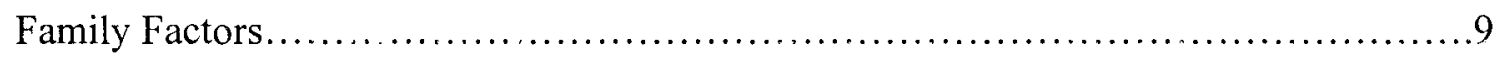

Parent psychopathology and family functioning $\ldots \ldots \ldots \ldots \ldots \ldots \ldots \ldots \ldots \ldots \ldots$

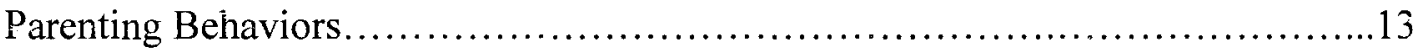

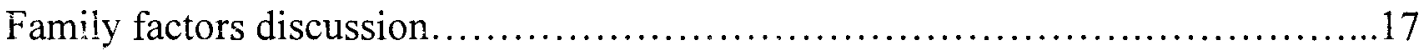

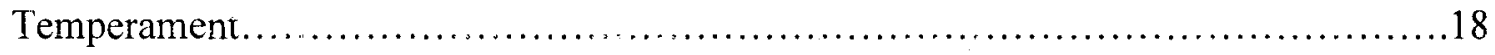

Reactivity and self-regulation............................................ 19

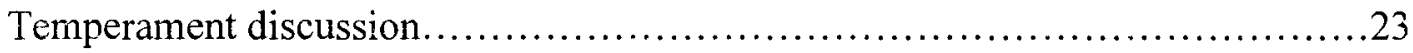

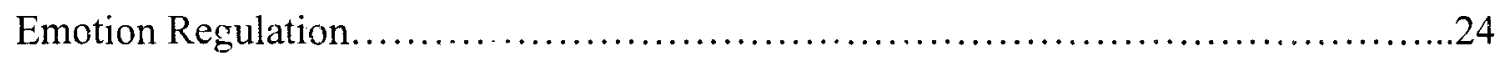

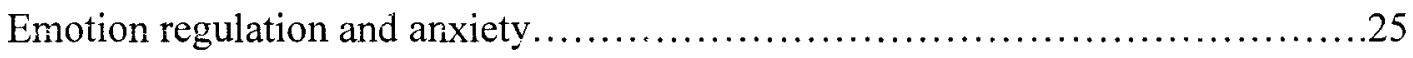

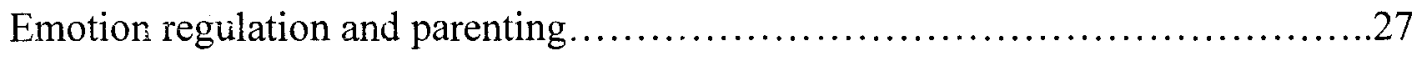




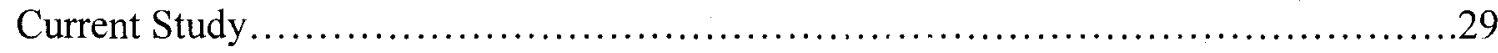

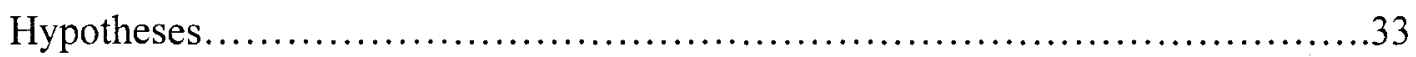

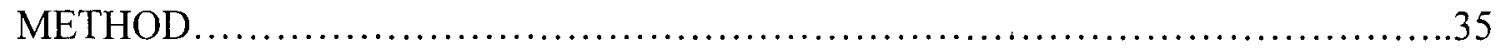

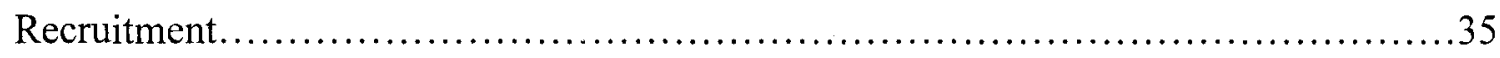

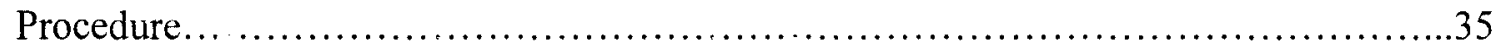

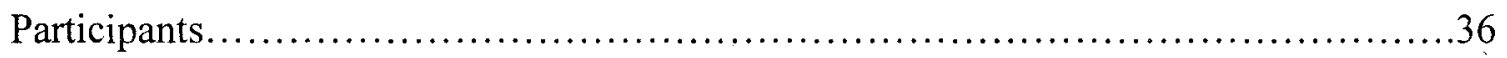

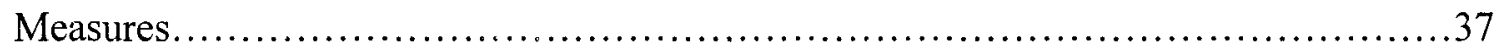

Parent report measures.......................................................

Parent self-report measures................................................ 38

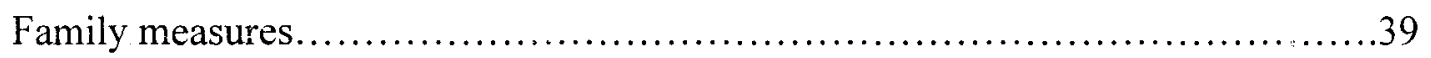

Child self-report measures...............................................40

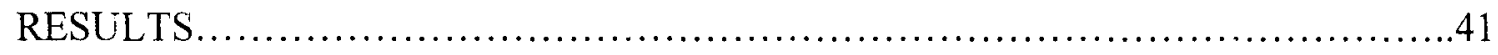

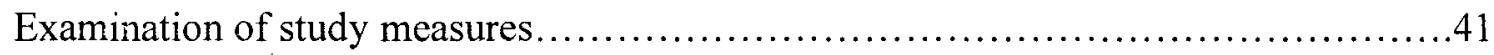

Examination of statistical assumptions......................................44

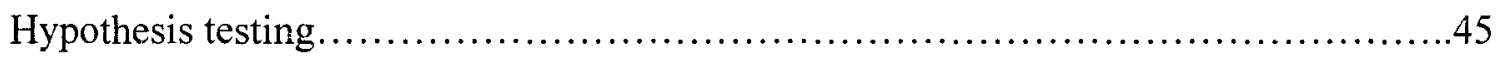

Level 1: examination of the relationships between child, parent, and family

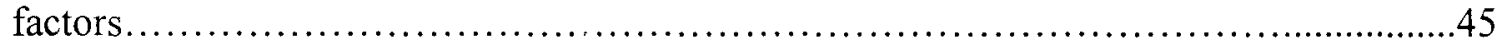

Level 2: Examination of the relationships between child, parent, and family factors,

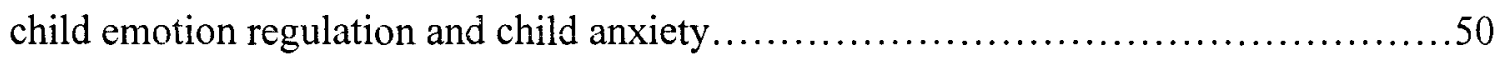

Level 3: Examination of child emotion regulation as a mediator of the relationship between child, parent, and family factors and child anxiety .........................54 


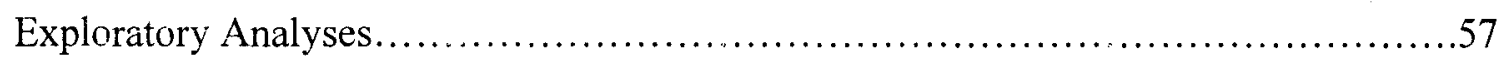

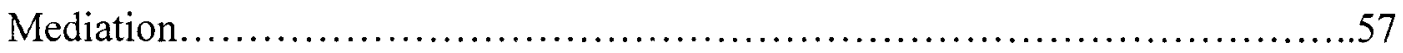

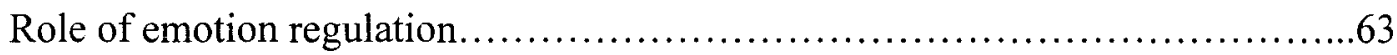

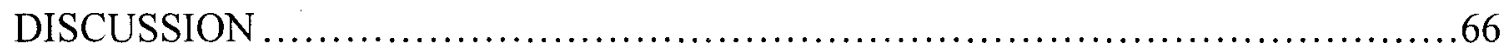

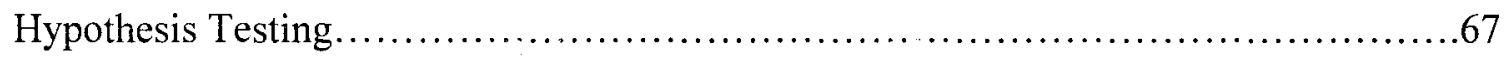

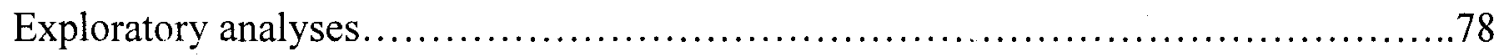

Implications for the conceptual model........................................... 81

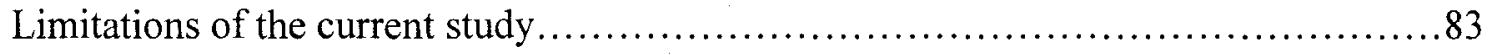

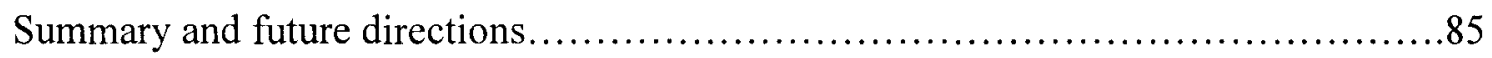

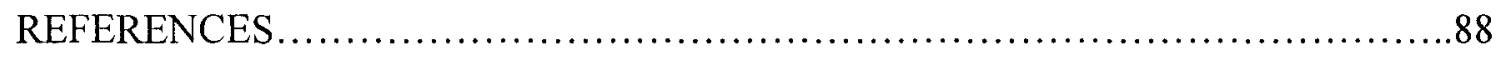

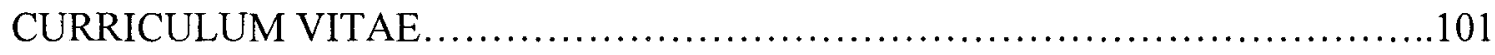




\section{LIST OF TABLES}

TABLE

PAGE

1. Descriptive Statistics for Study Measures............................43

2. Hypothesis One Correlation Results.................................46

3. Hypothesis Two Regression Results.............................47

4. Hypothesis Four Regression Results..................................49

5. Hypothesis Five Correlation Results......................................51

6. Hypothesis Six Correlation Results................................53

7. Hypothesis Seven Indirect Effect Results..........................56

8. Exploratory Analysis Indirect Effect Results.........................58

9. Exploratory Analysis Regression Results..........................65 


\section{LIST OF FIGURES}

FIGURE

PAGE

1. Hypothesized model of resilience ....................................... 31

2. Exploratory results with Emotion Control as mediator......................60

3. Exploratory results with Shift as mediator.............................62

4. Exploratory results with Inhibit as mediator.............................63

5. Graphical summary of hypothesis testing............................... 83 


\section{INTRODUCTION}

Epidemiological studies have shown that a significant number of children suffer from psychological disorders and approximately $36 \%$ of children and adolescents meet diagnostic criteria for at least one disorder before the age of 16 years (Costello, Mustillo, Erkanli, Keeler, \& Angold, 2003). Of these disorders, anxiety is one of the most common with prevalence rates ranging between 2-17\% (Costello, Egger, \& Angold, 2004; Grills-Taquechel \& Ollendick, 2007; Rapee, Schniering, \& Hudson, 2009). Anxiety disorders in childhood are disabling, often causing impairment in functioning across academic, social, and occupational domains (Rapee et al., 2009). Anxiety disorders are also often chronic in nature with disorders in childhood leading to an increased likelihood of developing anxiety and depression in adulthood (Bittner et al., 2007). In an attempt to understand the etiology of childhood anxiety, research has focused on identifying vulnerability and risk factors which might contribute to the development of anxiety in children (Gregory \& Eley, 2007; Hughes, Hedtke, \& Kendall, 2008; McLeod, Wood, \& Weisz, 2007; Murray, Creswell, \& Cooper, 2009; Nigg, 2006). Although invaluable in providing an initial framework to understand the development of anxiety and possible treatments, research on individual risk factors has failed to adequately explain the etiology of anxiety. Consequently, researchers in the field of developmental psychopathology have called for more integrative and holistic models, 
which consider the complex interplay between child and environmental factors in determining the developmental course of anxiety in children (Cicchetti \& Toth, 1997). In response, researchers in the field of child anxiety have begun to put forth more complex theoretical models of the etiology of child anxiety (Malcarne, Hansdottir, \& Merz, 2001; Vasey \& Dadds, 2001). Although promising, most still focus on the interplay of risk factors resulting in a narrow focus. Such a limited perspective fails to appropriately capture the dynamic mediating and moderating processes that may better explain the complex relationships between factors and child outcomes (Cummings, Davies, \& Campbell, 2000a). Identification of risk and protective factors and exploration of the transaction between them provides a more complete view of developmental trajectories and the processes which contribute to successful development despite adversity.

More recently, a theoretical model of resilience in children at risk for development of anxiety has been proposed focusing on the discontinuity between certain temperamental vulnerabilities (behavioral inhibition) and anxiety (Degnan, Almas, \& Fox, 2010; Degnan \& Fox, 2007). Dengan and colleagues have argued that behavioral inhibition (BI) is a significant and precipitating vulnerability factor to the development of anxiety such that discontinuity between child $\mathrm{BI}$ and later development of anxiety suggests an underlying resilience process (Degnan et al., 2010; Degnan \& Fox, 2007). They have proposed a model of resilience in which environmental factors such as parenting, peer relations, and childcare experiences moderate the relationship between $\mathrm{BI}$ and anxiety. Elaboration of such a model represents a much needed conceptual shift to a focus on factors leading to adaptive outcomes in anxiety research. Yet, a narrow focus on specific temperamental qualities as the initiating factor in the development of anxiety 
limits our understanding of resilience processes to children who are behaviorally inhibited, and not all children who develop anxiety are behavioral inhibited. Future research should consider the differential impact of multiple vulnerability, risk and protective factors on the development of anxiety, and how these factors influence one another across development to promote better psychological functioning.

The determination of which factors to include in a developmental model of anxiety is of optimum importance, and, consistent with a developmental psychopathology perspective, factors both intrinsic and extrinsic to the child should be considered. The inclusion of all possible factors contributing to the etiology of anxiety, although conceptually interesting, is not practical. Consultation of the research literature on child anxiety provides evidence for some key variables which should be considered.

Research has supported the intergenerational transmission of a genetic vulnerability in the development of anxiety disorders (Eley, 2001; Hettema, Prescott, Myers, Neale, \& Kendler, 2005). Twin and adoption studies suggest that approximately $30-40 \%$ of the variance in anxiety can be accounted for by genetic factors (Hettema, Neale, \& Kendler, 2001), and family aggregation studies have shown that children of anxious parents are 5-7 times more likely to develop anxiety as control families (Turner, Beidel, \& Costello, 1987). In addition, parent psychopathology may also play a role in the development of negative family environments (Nicholson, Sweeney, \& Geller, 1998). Poor family functioning and marital discord have been associated with parent anxiety (Ginsburg, Siqueland, Masia-Warner, \& Hedtke, 2004; Papp, Goeke-Morey, \& Cummings, 2004), and parent psychopathology has also been shown to impact the parentchild relationship (Belsky, 1984). 
Research has supported behavioral differences in interactions between anxious and non-anxious parent-child dyads including granting of autonomy (Moore, Whaley, \& Sigman, 2004), overcontrol (Hudson \& Rapee, 2001), aversiveness (Dumas, LaFreniere, \& Serketich, 1995), warmth (Whaley, Pinto, \& Sigman, 1999), and withdrawal (Woodruff-Borden, Marrow, Bourland, \& Cambron, 2002). More recent studies have supported an interaction in which both parent and child behavior influence the dyadic exchange (e.g. Schrock \& Woodruff-Borden, 2010), and current conceptualizations of anxiety point to the important role children themselves play in the developmental process (Dadds \& Roth, 2001).

As a result, child characteristics such as temperament have received considerable research attention and have been linked to a variety of positive and negative child outcomes including the development of conscience (Kochanska, 1993), social competence (Eisenberg \& Fabes, 1992), and psychopathology (Muris \& Ollendick, 2005). Rothbart's temperamental qualities of negative affect and effortful control appear to be particularly interesting in terms of anxiety (Lonigan \& Phillips, 2001), possibly contributing to the development of anxiety-related cognitive biases (Lonigan \& Vasey, 2009). These temperamental traits have also been shown to be open to environmental influence (Rothbart \& Putnam, 2002).

However, research on the associations between these factors and anxiety has supported only modest relationships between any one variable and anxiety. A logical step is to consider how these factors may act in concert and identify possible mediational relationships which may better explain the relationship of these variables to anxiety. Many of the same factors that have been shown to be related to the development of 
anxiety in children have also been shown to be associated with development of emotion regulation. For instance, certain child temperamental characteristics have been shown to be associated with the development of poor emotion regulation skills (Rothbart $\&$ Sheese, 2007), and studies have also shown that the development of emotion regulation skills can be influenced by the quality of parenting and the early child rearing environment (Field, 1994; Thompson, 1994).

The ability to flexibly and adaptively regulate emotional responses to internal and external stimuli has been shown to be a key process in the development of psychopathology and adaptive functioning (Southam-Gerow \& Kendall, 2002). The ability to marshal cognitive and behavioral resources to help regulate emotional responses has been shown to be related to positive outcomes such as social competence (Eisenberg \& Fabes, 1992), and poor emotion regulation skills have been shown to be related to adjustment problems and development of a variety of psychological disorders (Cicchetti, Ackerman, \& Izard, 1995; Lengua, 2003). The development of successful emotion regulation skills may represent a resilience process in child anxiety. Yet, few, if any studies, have explored how child and parent factors combine to influence the development of emotion regulation, or how this process might impact the development of anxiety in children.

The current paper explores several areas of research to propose and empirically test a model of resilience in children at risk for development of anxiety. First, developmental psychopathology as a framework for understanding the resilience process will be considered. Next, research on child temperament, parenting, family environment, and parent psychopathology and their interaction will be reviewed in relation to child 
anxiety. Research on the development of emotion regulation and its relationship to child anxiety will also be reviewed. Finally, a model of resilience will be proposed in which child emotion regulation mediates the relationship between child and parent factors and the development of child anxiety and portions of the proposed model will be tested.

\section{Resilience}

Developmental psychopathology is concerned with understanding the diverse impacts, both positive and negative. of environmental and genetic factors on the development of children's adaptive and maladaptive functioning (Cummings, Davies, \& Campbell, 2000b). Developmental psychopathologists view development as a transactional process between a constantly evolving child and changing environment (Cummings et al., 2000b). By examining the confluence of factors conferring risk, vulnerability, and protection, developmental psychopathologists can better understand the relationship between normal and abnormal development, thus providing a more solid foundation for prevention and treatment. Early research in the field focused on the identification of risk factors leading to the development of maladaptive behavior. Multiple factors associated with increased risk for poor child outcomes have been identified, such as low socioeconomic status, perinatal distress, parental mental illness, childhood maltreatment or abuse, neighborhood violence, chronic illness, and stressful life events (Luthar, 1991; Masten, Best, \& Garmezy, 1990; Rutter, 1990; Werner, 1989). In the process of exploring children at risk, developmental psychopathology researchers began to identify subsets of children who displayed positive adaptation despite adversity. In 1974, Garmezy detailed the progress of a number of developmental psychopathology studies evaluating the development trajectories of high-risk children of parents with 
severe mental illness (Garmezy, 1974; Garmezy \& Streitman, 1974). In his review, Garmezy described findings from several of the studies, including his own, in which high-risk children exhibited lower levels of psychopathology and better social functioning than would be expected given the great number of risk factors working against them. Later termed resilience, discovery of adaptive functioning despite severe risk and adversity led to a flurry of research aimed at identifying protective factors in atrisk children (For review see Luthar, 2006). In a groundbreaking longitudinal study of 698 infants born on the island of Hawaii, Werner and colleagues (1989) noticed a subset 201 children who due to increased incidence of significant risk factors were designated as "vulnerable". Children were deemed vulnerable if they experienced 4 or more of the following risk factors before their second birthday: moderate to severe perinatal distress, chronic poverty, under-educated parents, and family environments characterized by discord, divorce, and alcoholism or mental illness. Despite significant risk, 72 of the original 201 vulnerable children developed into healthy, socially competent adults. Researchers identified several factors which acted to buffer these children against risk, including the temperamental characteristics of low excitability and high sociability, coming from families with four or fewer children, having an opportunity to develop a supportive relationship with at least one caregiver, and use of a larger community of friends and elders for support. Current conceptualizations consider resilience as a dynamic process that is constantly unfolding across development allowing individuals to more successfully navigate adversity (Cummings et al., 2000a; Luthar, 2006). Resilience research then is the exploration of the transactional processes between intrinsic and 
extrinsic factors which promote psychological functioning and lead to better child outcomes (Luthar, 2006; Luthar, Cicchetti, \& Becker, 2000).

Over the last decade, researchers have begun to explore child anxiety from a developmental psychopathology perspective attempting to provide more complex, integrative models with which to conceptualize the development of anxiety (Vasey \& Dadds, 2001). Significant strides have been made across a wide body of research literatures, and several attempts have been made to synthesize these literatures in relation to child anxiety (Fox, Henderson, Marshall, Nichols, \& Ghera, 2005; Murray et al., 2009; Vasey \& Dadds, 2001). Yet, empirical studies on child anxiety have predominantly focused on identifying risk factors that may influence the development and maintenance of anxiety in children. Although research on risk has been invaluable in providing information on mechanisms involved in the progression of anxiety, it has failed to fully explain the developmental pathways of anxiety. One reason for this shortcoming may be that, from a developmental psychopathology perspective, identification of risk is only one part of the larger transactional model. Exploration of the transactional process leading to adaptive child outcomes is as important to our understanding of developmental psychopathology as vulnerability and risk. Research on the etiology of child anxiety needs to transition to a more holistic and process oriented approach which considers how multiple factors act in concert over time to produce both adaptive and maladaptive child developmental outcomes. Context is vital when considering developmental pathways, and research has pointed to the family environment as the primary socialization agent for the child (Stark, Humphrey, Laurent, Livingston, \& Christopher, 1993). 


\section{Family Factors}

\section{Parent psychopathology and family functioning}

Parent anxiety is thought to contribute to the development of anxiety in children directly via genetic influences and indirectly through the impact on the family environment (Fristad \& Clayton, 1991; Ginsburg et al., 2004; Gregory \& Eley, 2007; Hettema et al., 2001; Nicholson et al., 1998). Family functioning is believed to be influenced by parent anxiety and aspects of family functioning including marital satisfaction and discord are thought to influence child psychosocial functioning (Belsky, 1984; Frey \& Oppenheimer, 1990; Ginsburg et al., 2004).

Genetics studies have consistently supported a familial relationship in anxiety disorders (Gregory \& Eley, 2007). Using a twin design, Eley (2001) found approximately $30 \%$ of the variance in anxiety disorders was accounted for by genetic factors. In a meta-analysis of twin design genetic studies of anxiety, Hettema (2001) found support for moderate heritability of anxiety disorders with genetic factors accounting for $43 \%$ percent of the variance in panic disorder and $32 \%$ percent of the variance in generalized anxiety disorder. Family aggregation studies using top-down and bottom-up designs have also supported the familial nature of anxiety. In a series of studies by Biederman and colleagues, children of parents with panic disorder were more likely to be diagnosed with an anxiety disorder themselves, and parents of children with anxiety disorders were shown to have an increased rate of anxiety disorders compared to controls (Biederman, Petty, Faraone, et al., 2006; Biederman et al., 2005; Biederman, Petty, Hirashfeid-Becker, et al., 2006). Beidel and Turner (1997) found similar results in a sample of children with parents diagnosed with anxiety, depression or mixed anxiety 
and depression. The design of family aggregation studies explores the relationship between parent and child anxiety as either due to genetic factors or differences in family environment instead of the possible convergence of these factors. Although genetic studies do support a family-based genetic vulnerability for anxiety, these studies also only show a moderate degree of heritability. From a developmental psychopathology perspective it is important to explore the combined influence of both the direct genetic influence of parent anxiety and also the impact anxiety may have on the family unit.

Although most research on the impact of psychopathology on parent psychosocial and family functioning has been with depressed parents, parent anxiety has been associated with poor overall family functioning (Chapman \& Woodruff-Borden, 2009), increased marital conflict and divorce (Frey \& Oppenheimer, 1990; Jekielek, 1998), poor marital quality (Nomura, Wickramaratne, Warner, Mufson, \& Weissman, 2002), increased family dysfunction (Fristad \& Clayton, 1991), and difficulties parenting (Bogels \& Brechman-Toussaint, 2006). Each of these facets of family functioning has been associated with child adjustment problems (Cummings, 1994; Dadds \& Powell, 1991; Fincham, Grych, \& Osborne, 1994). Hughes, Hedtke, and Kendall (2008) compared self-reported family functioning in a sample of 179 anxiety disordered children and their families and 52 control families. The authors reported that maternal and paternal reports of overall family functioning were associated with child anxiety. However, research on general family functioning has been mixed, and studies focusing on specific aspects of family functioning have shown more consistent results. In a study by Peleg-Popko and Dar (2001), 108 mothers with 5-6 year old children were asked to complete measures of marital quality, family cohesion, and child anxiety. Results from 
the study showed that marital quality was inversely related to family cohesion and child specific phobias. High family cohesion and low adaptability were related to child social anxiety. The authors suggest that families with low marital quality are characterized by discord and emotional intensity which may diminish parents ability to be effective providers of emotional support for their children (Peleg-Popko \& Dar, 2001). In a similar study by Papp, Goeke-Morey, and Cummings (2004), mother and fathers from 51 families with children 4 to 10 years of age were asked to complete measures of psychological symptoms and distress, family adjustment, and child behavior. The authors reported a reiationship between psychological symptoms and less marital satisfaction with the relationship between symptoms and satisfaction predicting child behavior problems. They also reported that maternal marital satisfaction appeared to buffer children from maternal psychological symptoms and stress. Cummings and Davies (2002) have proposed a model for the impact of marital conflict on child functioning in which conflict resolution plays a significant role in how children react to marital conflict. As part of a larger longitudinal study, Goeke-Morey, Cummings, and Papp (2007) asked mother and fathers from 90 families to maintain a family diary on family conflict and conflict resolutions. Children in the families were asked to participate in an analog conflict resolution task during which they were interviewed regarding several videos of family conflicts with different resolutions. Results from the study revealed that conflict resolution lessened the impact of negative or even hostile parent conflicts, and children's response at the end of conflicts predicted child adjustment. In a second study on conflict resolution by Cummings, Goeke-Morey, and Papp (2003), 116 mothers and fathers with children 8-16 years old were asked to maintain dairy reports on marital conflicts and fill 
out measure of marital functioning, conflict tactics, hostility, and child behavior. The authors reported that negative conflict tactics were related to negative child emotions and positive conflict tactics were associated with positive child emotions. The authors suggest that exposure to marital conflict may undermined or reinforce children's sense of emotional security depending on type of conflict tactics employed.

Research on parent psychopathology and family functioning supports a multifaceted and complex system of genetic and environmental factors interacting to influence child psychosocial functioning. Children living in families with poor marital quality or satisfaction and poor overall family functioning likely endure increased life stress. Several researchers have commented on the impact of marital conflict on children's emotional responses and coping, proposing that how parents engage in and resolve marital conflict might impact children's abilities to develop coping mechanisms and regulate their own emotional responses (Fincham et al., 1994; Peleg-Popko \& Dar, 2001). It is also necessary to consider how parent anxiety may impact parent behavior within the larger family system. For example, how parent anxiety might influence parent behavior, decision making, and problems solving in terms of marital conflict and conflict resolution, and in turn how might these factors impact child outcomes? Conversely, increased marital satisfaction or marital quality might act as protective factors against parent psychological symptoms of stress. It could be that parents in good marital relationships rely on each other for emotional support combining resources to help achieve effective parenting. Overall, the literature suggests that parent anxiety and family functioning impact the behavior of parents and children and influences the parentchild relationship, shaping the ways parents and children interact (Belsky, 1984; 
Cummings \& Davies, 2002; Fincham et al., 1994). Parent behavior in various contexts may influence child development trajectories and researchers have explored the impact of specific parenting behaviors on the development of child anxiety.

\section{Parenting Behaviors}

The impact of parenting on child anxiety has received considerable attention in the research literature over the last 20 years. Research on parenting behaviors initially focused on the differences between anxious and non-anxious parents or the parents of anxious and non-anxious children and has established that anxious parents and parents of anxious children are more controlling, more negative, less warm, less granting of autonomy, and tend to withdraw from interactions (Hudson \& Rapee, 2001; Siqueland, Kendall, \& Steinberg, 1996; Turner, Beidel, Roberson-Nay, \& Tervo, 2003; Whaley et al., 1999; Woodruff-Borden et al., 2002). In a study by Gar and Hudson (2008) children were asked to prepare a 1 to 3 minute speech to be presented to the experimenter and to complete a self-report measure of anxiety symptoms. The sample consisted of 135 mothers and their 4-16 year old children. Mothers and children were grouped based on anxiety status. In a second task, mothers were asked to complete a 5 minute speech task describing their child and to complete a parent report measure on child anxiety symptoms. Seventy-one dyads completed both tasks. Tasks were videotaped and parent behaviors were coded into the global composites of over-involvement and negativity for the child speech task and emotional over-involvement and criticism for the maternal speech task. Results from the child speech tasks revealed that mothers of anxious children were rated as more over-involved than mothers of non-anxious children regardless of maternal anxiety status. Results from the maternal speech task showed that mothers of 
anxious children were more overinvoived, self-sacrificing, non-objective, and critical than mothers of non-anxious children. Hudson, Doyle, and Gar (2009) asked 91 children (45 anxious and 46 non-clinical controls) ages 7 to 14 years and their mothers to participate in a child speech task. Children in the study were asked to prepare a 5 minute speech to be delivered to the experimenter. Mothers were given the instructions that the speech was meant to test the child's presentation and social skills and that they could help if they felt the child needed assistance. Mothers were then paired with two children, not their own, one of whom matched their child's anxiety status and one who did not. Mothers and children were also asked to complete several self-report and parent measures of child functioning and anxiety symptoms. Results showed that during speech interactions with children who were not their own, mothers of anxious children were observed to be more involved with anxious in comparison to non-anxious children. Mothers of anxious children were also rated as less negative with non-anxious children in comparison to anxious children. The authors propose that the results from the study support the influence of children's anxious behaviors on maternal behaviors in the interaction, specifically over-involvement. Although differences in the behavior of anxious and non-anxious parents or the parents of anxious and non-anxious children have been supported in the literature, effect sizes have traditionally been small and the significance of the results is often clouded by shortcomings in research designs or difference in the definitions of observed behaviors (McLeod et al., 2007; van der Bruggen, Stams, \& Bogels, 2008; Wood, McLeod, Sigman, Hwang, \& Chu, 2003). Several meta-analytic studies have been completed which consolidate research on parenting behavior and anxiety. Wood, McLeod, Sigman, Hwang, and Chu (2003) 
completed a review of 21 studies on the relationship between child anxiety and parent warmth, control and modeling of anxious behavior. Parent control showed a consistent link with child anxiety, but only when using observational measures of parent-child interactions. The authors concluded that significant variability in study design and assessment methodology led to inconsistent results limiting conclusions regarding the impact of parenting behaviors. The authors also commented on the need to clarify the direction of effects between parenting and child anxiety. In another review of literature, Bogels and Brechman-Toussaint (2006) reached a similar conclusion in regard to parent control and child anxiety. The authors point out that the bulk of research in the area is cross-sectional in design and provides no clear picture as to whether parent control plays a role in the development of child anxiety or whether child anxiety influences parent control. A meta-analytic review of parenting and child anxiety (McLeod et al., 2007) examined the contributions of the parenting dimensions of rejection and control. Results showed a small effect size for parental rejection and a medium effect size for parental control, accounting for $4 \%$ and $6 \%$ of the variance in child anxiety respectively. Further analysis of rejection and control revealed small effect sizes for the parenting subdimensions of warmth, withdrawal, aversiveness, and over-involvement, and a large effect size for autonomy granting. The authors suggest that their findings support a small contribution of parenting to child anxiety. In a second, meta-analysis of 28 observational studies on the relationship between parent control and parent and child anxiety, the authors reported a medium to large effect size linking child anxiety and parenting control, but no significant relationship between parent anxiety and parent control (van der Bruggen et al., 2008). The authors identified several variables which moderated the 
relationship between parent control and child anxiety including parent gender, socioeconomic status, type of child anxiety, study design, type of interaction task, child gender, and child age.

Overall, research on parenting behaviors appears to support at least a moderate role of parenting behaviors, particularly control, in the development of child anxiety. However, the picture is far from clear and questions still remain regarding the direction of effects, the impact of child factors such as age and gender, and the mechanisms by which parenting behaviors such as control might influence child anxiety. Theoretical models have suggested that parenting behaviors, such as control, limit anxious children's ability to develop effective coping mechanisms (Dadds \& Roth, 2001). Yet, despite significant theoretical backing, there have been few, if any studies examining the impact of specific parenting behaviors on children's ability to develop effective coping and regulation strategies. From a developmental psychopathology perspective, it is important to consider that parent behavior most likely varies as a function of the age and maturity of the child being parented. The impact of parenting may be greater on younger children who are more dependent on parents for guidance and regulation of emotion and behavior responses to stress. However, as children grow older they become more independent from parents and may rely more heavily on friends and peers for support. It may also be important to consider mismatches between parenting and child age. Current research has implicated parent control in the development of child anxiety, but parent control may be more or less appropriate depending on child age. The same could be argued for granting of autonomy, which may function to encourage independence and confidence in oider children but may leave a much younger child feeling unsupported. Research on parenting 
behaviors in child anxiety has found little support for age as a significant moderator, but the vast majority of research in the field has been cross-sectional using narrow age ranges of school aged children (McLeod et al., 2007; van der Bruggen et al., 2008). As studies examine the longitudinal development of anxiety, child developmental markers such as age or measures of cognitive functioning may be important in understanding the differential impact of parenting on child anxiety.

\section{Family factors discussion}

Etiological models of parenting and child anxiety suggest that parent and child factors cannot be viewed in isolation but as an interactive system in which both members influence the relationship (Dadds \& Roth, 2001). Only a few studies have explored parent-child interaction at the level of the dyad and results have supported significant contributions of both parent and child (Dumas et al., 1995; Moore et al., 2004; Schrock \& Woodruff-Borden, 2010; Whaley et al., 1999). It has been suggested that the anxiety interferes with parents' ability to appropriately assist children in navigating stressful situations. Lack of parent support could lead to chronic underestimation of coping abilities and reinforce maladaptive coping strategies. Difficulties within the family unit such as marital discord may leave parents isolated with little or no support and expose children to increased stress and models of maladaptive coping and regulation skills. Conversely, a healthy marriage could provide anxious parents with much needed emotional support and help buffer children from the negative consequences of parent psychopathology. The influence of the family environment most likely waxes and wanes over time depending on where children are in the developmental process. For instance, the family environment may be most influential when children are younger or at key 
transitional periods such as starting school. Consideration of how and when these factors are important and what developmental processes are being shaped are crucial questions in our understanding of the developmental course of anxiety. In order to fully appreciate the developmental process of anxiety, research must consider the confluence of genetic and environmental factors which converge to determine adaptive and maladaptive developmental trajectories. In terms of family environment, this includes the behavior of parents and children as an interactive process with each member of the interaction influencing the other within the broader context of the family unit. Research has supported children as active agents in the developmental process reacting to and influencing their environment (Clark, Kochanska, \& Ready, 2000; Dumas et al., 1995). As such, it is necessary to consider factors intrinsic to the child and how these factors may contribute to the broader developmental process. One area of considerable interest in the child anxiety literature has been child temperament.

\section{Temperament}

Temperament has been described as, "biolegically rooted individual differences in behavior tendencies that are present early in life and are relatively stable across various kinds of situations and over the course of time" (Bates, 1987, p. 1101). Several conceptualizations of temperament have been proposed including Buss and Plomin's (1975) model of emotionality, activity, and sociability and the nine factor model proposed by Thomas and Chess (1977). Most theories of temperament contain aspects of activity level, emotionality, and behavioral responses to novel stimuli. Several studies have reported on the stability of child temperament (Caspi et al., 2003; Caspi \& Silva, 1995), but relationships with adult personality have only been modest indicating some 
level of discontinuity across development. Recent work in the field of child temperament has supported a relationship between the temperamental traits of reactivity and selfregulation and anxiety (Rothbart, Ellis, \& Posner, 2004; Rothbart \& Putnam, 2002).

\section{Reactivity and self-regulation}

Rothbart (2004) has defined temperament as relatively stable, biologically-based differences in reactivity and self-regulation, which are influenced by individual experience and environment. Temperamental reactivity usually refers to the onset, intensity, and duration of emotional, motor, and orienting reactions (Rothbart \& Putnam, 2002). Self-regulation refers to processes that serve to modulate reactivity including attentional strategies, approach and withdrawal behaviors, and executive functioning (Rothbart \& Sheese, 2007). The factors of reactivity and regulation have been shown to be stable across a wide age range (Durbin, Hayden, Klein, \& Olino, 2007; Rothbart, 1986; Rothbart, Ahadi, \& Evans, 2000) with some studies supporting the relationship between child temperament and adult personality (Ahadi \& Rothbart, 1994; Caspi \& Silva, 1995). Yet, the research has also provided evidence for the influence of environmental factors on the development of temperamental characteristics (Kochanska, 1995; Kochanska, Murray, \& Harlan, 2000). Rothbart's conceptualization of temperament includes the factors of negative affect (reactivity), surgency (reactivity) and effortful control (self-regulation) (Rothbart et al., 2000). Effortful control and negative affect have received the most attention from researchers, and theoretical work has hypothesized a relationship between high negative affect, low effortful control, and anxiety (Muris \& Ollendick, 2005; Nigg, 2006; Rothbart et al., 2000). 
Negative affect (NA) has been defined as a disposition toward feelings of nervousness, tension, anger, guilt, self-dissatisfaction, and a sense of rejection and sadness (Watson \& Clark, 1984). Several studies have supported a relationship between child NA and internalizing symptoms in middle childhood and early adolescence. Adolescents 10-17 years of age completed measures of self-reported temperament, anxiety, and depression (Anthony, Lonigan, Hooe, \& Phillips, 2002). Regression analysis revealed a significant relationship between adolescent NA and measures of anxiety and depression. Additional support for the relationship between NA and anxiety comes from a longitudinai study of 303 children followed from ages $2-6$ years in which high NA was associated with increased internalizing symptoms, but only in high fearful children (Gilliom \& Shaw, 2004). Findings from another longitudinal study by Lengua and Kovacs (2005) showed a bidirectional relationship between child NA and inconsistent parenting, both of which significantly predicted internalizing problems in children $8-11$ years of age.

Effortful control (EC) refers to the ability to voluntarily and adaptively focus attentional resources to modulate emotional and behavioral responses to stimuli (Rothbart et al., 2004; Rothbart \& Putnam, 2002). Development of EC has been related to a variety of positive and negative child outcomes. For instance, Kochanska et al. (2000) assessed 106 children as part of a longitudinal study of child EC and maternal behavior. Children were assessed at 9, 22, and 33 months of age. The authors reported that EC was related to greater attention focusing at 9 months and maternal responsiveness and socialization at 22 months. Greater EC was also related to better emotion regulation and behavioral restraint. However, it has been the combination of high NA and low EC that has been 
suggested to place children at risk for development of internalizing and externalizing disorders (Muris \& Ollendick, 2005; Nigg, 2006). For example, in a community sample of 101 children ages 8-12 years, Lengua (2002) reported differences in emotionality and the ability to self-regulate, as assessed by observational and self-report measures of EC and positive and negative emotionality, predicted adjustment problems. In a second study by Lengua (2003) using a community sample of 3-5 year-olds, differences in positive and negative emotionality and self-regulation predicted internalizing and externalizing symptoms.

Lonigan, Vasey, Phillips, and Hazen (2004) have suggested that individuals with high NA and low EC are prone to experiencing intense negative emotions and have difficulty regulating attentional resources to disengage from threatening stimuli. Furthermore, it has been hypothesized that an inability to regulate attentional resources in the face of threat is linked to the development of a key cognitive component of anxiety disorders - attentional bias toward threat (Dadds \& Roth, 2001; Lonigan \& Phillips, 2001). Consequently, these individuals will likely have trouble implementing effective coping strategies to regulate their emotional experiences. Recent studies have supported a relationship between NA and EC and attentional bias toward threat, and also the relationship between high NA, low EC and anxiety. Empirical support for the relationship between temperament and attentional bias comes from a study conducted by Lonigan and Vasey (2009) with 104 children and adolescents ages 10-19 years. Participants were assessed on self-report measures of anxiety, negative and positive affect, and EC, and a computer-based dot-probe task to assess attentional bias to threat 
related words. Results indicated that children and adolescents who scored high on NA and low on EC demonstrated a significant bias toward threat words.

Better EC has been associated with several positive child outcomes including better social functioning, better emotion regulation, and the development of conscience (Kochanska, 1993; Kochanska et al., 2000; Rothbart \& Sheese, 2007). In combination with high NA, low EC have been implicated in the development of psychopathology in children. Unfortunately, support for a relationship between these temperamental characteristics and anxiety has been mixed, with many studies suggesting connections with both internalizing and externalizing disorders (Muris \& Ollendick, 2005). One possibility is that differences in contextual factors may at least partially explain differences in developmental trajectories. Conceptual work in the field has posited that these temperamental characteristics are open to environmental influence, and empirical studies have supported this supposition (Lonigan \& Phillips, 2001).

Parenting factors have been shown to impact the development of self-regulation in children (Rothbart \& Putnam, 2002). Child temperamental characteristics such as positive and negative emotionality, irritability, fearfulness, and EC have been shown to be related to parent personality characteristics and quality of parent-child interactions (Belsky, Fish, \& Isabella, 1991; Kochanska et al., 2000; Lengua \& Kovacs, 2005). Colman, Hardy, Albert, Raffaelli, and Crockett (2006) conducted a longitudinal analysis of child self-regulation abilities and parenting characteristics. The study found that lower levels of punitive discipline and higher levels of maternal warmth at ages 4-5 years predicted better self-regulation in children at 8-9 years of age. Another recent longitudinal study by Degnan, Henderson, Fox, and Rubin (2008) explored temperament 
and parenting in children 4 months to 7 years of age. The authors reported that high depression and neuroticism in mothers was related to the stability of children's negative and reactive temperament. Additionally, maternal overprotective behavior predicted children's preschool social reticence. The authors suggest that overprotective maternal behavior, although well intended, interferes with the child's ability to develop skills to regulate their reactions to novelty and inhibits development of independence.

\section{Temperament discussion}

Current temperament theory focuses on biologically-based individual differences in reactivity and EC (Rothbart \& Sheese, 2007), and research has supported the role of these temperamental constructs in both positive and negative child outcomes. Research has also supported the role of external factors such as parents in the development and modification of reactivity and EC. Development is a crucial factor in Rothbart's theory of temperament. According to Derryberry and Rothbart (1997) the temperamental attribute of EC refers to an individual's ability to flexibly and adaptively utilize attentional resources to modulate reactivity. Thus, the temperamental attribute of EC is dependent on development of attentional circuits in the brain. More specifically, the development of the posterior attentional system, which is responsible for the engaging and disengaging of attention, the anterior attentional systems, which is viewed as an executive system helping to regulate the posterior attentional system, and the reticular activating system, which is responsible for attention focusing are key components in the functioning of selfregulation. The ability to effectively self-regulate requires all three attentional systems working in concert. Research has supported maturation of these attentional systems at different deveiopmental periods (Derryberry \& Rothbart, 1997). A review of the 
development of self-regulation from infancy to preschool age has been conducted by Kopp (1982). Newborn infants engage in self-regulation through self-soothing behaviors such as finger sucking or disengaging gaze from aversive stimuli, but use of more complex self-regulation, such as inhibitory control, does not develop until ages 3-6 years. It is important to consider whether differences in EC are due to deficits in the development of attentional systems, developmentally inappropriate tasks, or comparisons across too wide an age range. In considering resilience, there is evidence to support parenting, family environment, parent anxiety, and temperament as vulnerability, risk, and protective factors in the development of anxiety in children, and evidence to also support a transactional relationship between these variables. Yet, as reviewed, the strength of the relationships between genetic and family factors and anxiety are modest, discontinuity exists between temperament factors and anxiety, and in many instance there is a lack of specificity with factors relating to more than one type of disorder. Research has shown that many of the same factors that impact the development of anxiety also shape the development of emotion regulation (Belsky, 1984; Calkins \& Hill, 2007; Field, 1994; Fincham et al., 1994), and research has also indicated a link between emotion regulation and anxiety (e.g. Cisler, Olatunji, Feldner, \& Forsyth, 2010). Development of emotion regulation in children may represent a resilience process mediating the relationship between child, parent, and family factors and anxiety.

\section{Emotion Regulation}

Definitions of emotion regulation vary across studies, and one of the main challenges for researchers is developing a consistent and inclusive definition of the process of emotion regulation. Thompson $(1994$, p. 27) has referred to emotion regulation 
as, "extrinsic and intrinsic processes responsible for monitoring, evaluating, and modifying emotional reactions, especially their intensive and temporal features, to accomplish one's goals." Thompson (1994) also described several potential ways to regulate emotion including neurophysiological processes, attentional processes, differences in information processing (attributions and interpretations), coping resources, utilization of environment, and behavioral responses. Eisenberg and colleagues have conducted numerous longitudina! and cross-sectional studies examining child temperament, emotion regulation, and the development of social competence. For instance, child temperament, regulation and coping abilities were associated with child social competence in 91 children ages 52-76 months (Eisenberg, Fabes, Bernzweig, \& Karbon, 1993). Children lower in emotional intensity and with better regulation strategies were rated as more socially competent by parents and school personnel. In a second study of 82 children ages 71-108 months, Eisenberg et al. (1995) reported that child social competence varied as a function of emotional disposition and intensity and ability to regulate emotion over a two year period. Conversely, deficits in emotion regulation abilities have been consistently associated with psychopathology (Cicchetti et al., 1995). Yet, only a few studies have explored emotion regulation in relation to anxiety disorders.

\section{Emotion regulation and anxiety}

Salters-Pedneault, Roemer, Tull, Rucker, and Mennin (2006) examined emotion regulation in a large sample of adults ages 18-62 years diagnosed with generalized anxiety disorder (GAD) and found deficits in emotional clarity, acceptance of emotions, ability to engage in goal-directed behavior, impulse control, and ability to initiate 
effective coping strategies. In another study conducted by Baker, Holloway, Thomas, Thomas, and Owens (2004), aduits with panic disorder showed significant difficulties processing emotions compared to adults without panic disorder. Results from the study characterized participants with panic disorder as exhibiting overcontrol of emotional expression, hypervigilance of the onset of emotion, and having difficulty labeling emotions. Problems with emotion regulation have also been found in children with anxiety disorders. In a study of 28 children with anxiety disorders and 26 controls children, children with anxiety disorders and mothers rated their ability to adaptively regulate emotions and their confidence in their ability to regulate emotions significantly lower than control children and their mothers (Suveg, Zeman, Flannery-Schroeder, \& Cassano, 2005). Additionally, Zeman, Shipman, and Suveg (2002) documented an association between poor, self-reported emotion regulation strategies and internalizing symptoms in 227 children ages 9-12 years. More specifically, poor emotion awareness, inhibition of anger, and excessive expression of anger and sadness predicted internalizing symptoms. Researchers have hypothesized that children of parents with anxiety and depression are at greater risk for developing problems with emotion regulation due to lack of parental emotional support, modeling of maladaptive coping behaviors, and parent-child interactions that undermined the child's perceptions of their own coping abilities (Garber \& Dodge, 1991; Zahn-Waxler, Kochanska, Krupnick, \& McKnew, 1990). Several researchers have suggested that parents have a significant impact on the development of effective emotion regulation in children (Calkins \& Fox, 2002; Rothbart, Posner, \& Kieras, 2006; Thompson, 1994). 


\section{Emotion regulation and parenting}

Calkins and colleagues have proposed a bi-directional model of the development of emotion regulation in children, in which the child temperamental qualities of reactivity and regulation interact with parent strategies to help children regulate emotional arousal (Calkins, 1994; Calkins \& Hill, 2007). Several studies have supported the influence of parents on their children's capacity to develop effective emotion regulation strategies. Calkins and Johnson (1998) assessed factors contributing to children's emotion regulation behaviors at 18 months in an observational study of mother-child interactions. Results from the study indicated that toddlers who most often used active regulation strategies such as distraction to cope with frustration and distress had mothers who engaged in more positive toddler guiding behaviors. In a follow-up study, maternal negative interaction style was associated with poor physiological and emotion regulation and non-compliant child behavior (Calkins, Smith, Gill, \& Johnson, 1998). Finally, Feng et al. (2008) conducted a study involving 37 children with mothers who had a history of depression and 25 children with mothers with no psychiatric history. Dyads were assessed at age 4 years on measures of child temperament, child emotion regulation, and maternal interactive style. Researchers reported that among children of depressed mothers BI was associated with passive regulation strategies and sadness, while maternal positivity was associated with active regulation strategies and positive mood. Results from these studies provide support for the development of emotion regulation as an interactive process between parents and children, but most studies have focused on the relationship between emotion regulation and increased social competence in children (Calkins \& Hill, 2007; Eisenberg, Hofer, \& Vaughan, 2007). A few studies have 
supported a relationship between emotion regulation and child anxiety, and parenting appears to play a role in this relationship. Yet, little research has been done exploring differential impact of child temperament and parenting on the development of emotion regulation in children, or how these factors combine to influence the development of anxiety.

\section{Emotion regulation and temperament}

One area of particular importance in a potential model of child anxiety is the relationship between the temperamental characteristics of reactivity and EC and emotion regulation. Bosquet and Egeland (2006) investigated the connection between reactivity, regulation, and anxiety in a longitudinal sample of 155 parents and children. Children ages birth to 16 years were assessed at several time periods including infant, preschool, childhood, preadolescence, and adolescence. A multitude of observational and selfreport data were collected on reactivity, emotion regulation, social and academic competence, and anxiety. Results from the study supported a complex model in which infant reactivity and regulation predicted poor emotion regulation in preschool, poor emotion regulation predicted anxiety in childhood, and anxiety in childhood predicted low social functioning in adolescence.

According to Rothbart, "[w]e do not treat temperament and emotion regulation as distinct entities, nor do we claim that temperament causes emotion regulation, or that emotion regulation causes temperament. We further recognize that emotion regulation strategies go far beyond temperament, although temperamental characteristics may influence their development" (Rothbart \& Sheese, 2007, p. 333). It may be the temperamental quality of EC and the development of attentional and executive systems 
that initially place the upper limit on mental resources available for emotion regulation. However, research has shown that EC is open to environmental influence (Rothbart \& Putnam, 2002), and it is this socialization process that allows for the modification of attentional systems and ultimately leads to the acquisition and development of more complex regulation strategies. By definition, emotion regulation includes the utilization of attentional resources and executive function in the modulation of emotions, but emotion regulation is also concerned with the socialization of emotion and the monitoring, evaluative, and regulatory processes that development based on external influences (Thompson, 1994). One of the potential differentiating factors between temperament and emotion regulation is the development and acquisition of more complex regulation strategies through the process of socialization and learning. Examples of such strategies would be the use of meta-cognitive skills to re-evaluate and alter attributions, the utilization of individual coping resources/strategies such as meditation, the use of interpersonal (parents or peers) and material (music or television) environmental resources, or the use of emotions themselves as regulators. Despite a theoretically strong relationship between temperament and emotion regulation, little research has been done to empirically explore and support this connection. Additionally, socialization of emotion appears to play a significant role in the acquisition and adaptation of regulation strategies, and it follows that environmental factors, such as parenting and family environment, would play a critical role in this process.

\section{Current Study}

The current study proposes a model of resilience in children at risk for the development of anxiety and takes the first steps in validating the proposed model. 
Research has supported interactive relationships between child temperament, parenting, parent psychopathology, and family environment and their relationship to child anxiety (For review see: Bögels \& Brechman-Toussaint, 2006; Murray et al., 2009). Yet the strengths of the associations between these factors and anxiety are at best modest. Research has also supported a relationship between many of these same variables and the development of emotion regulation (Calkins \& Hill, 2007; Eisenberg, Cumberland, \& Spinrad, 1998; Rothbart \& Sheese, 2007), and the development of emotion regulation and anxiety (Salters-Pedneault et al., 2006; Southam-Gerow \& Kendall, 2002). A logical progression would be to propose and test a model in which emotion regulation mediates the relationship between child temperament and parent and family factors and the development of anxiety in children. Support of a mediation model such that development of better emotion regulation leads to better child outcomes is evidence of a resilience process. Moreover, exploration of the dynamic interchange of vulnerability, risk, and protective factors could provide significant insight into the developmental course of anxiety and effective avenues for prevention and treatment. 
Figure 1.Hypothesized model of resilience.

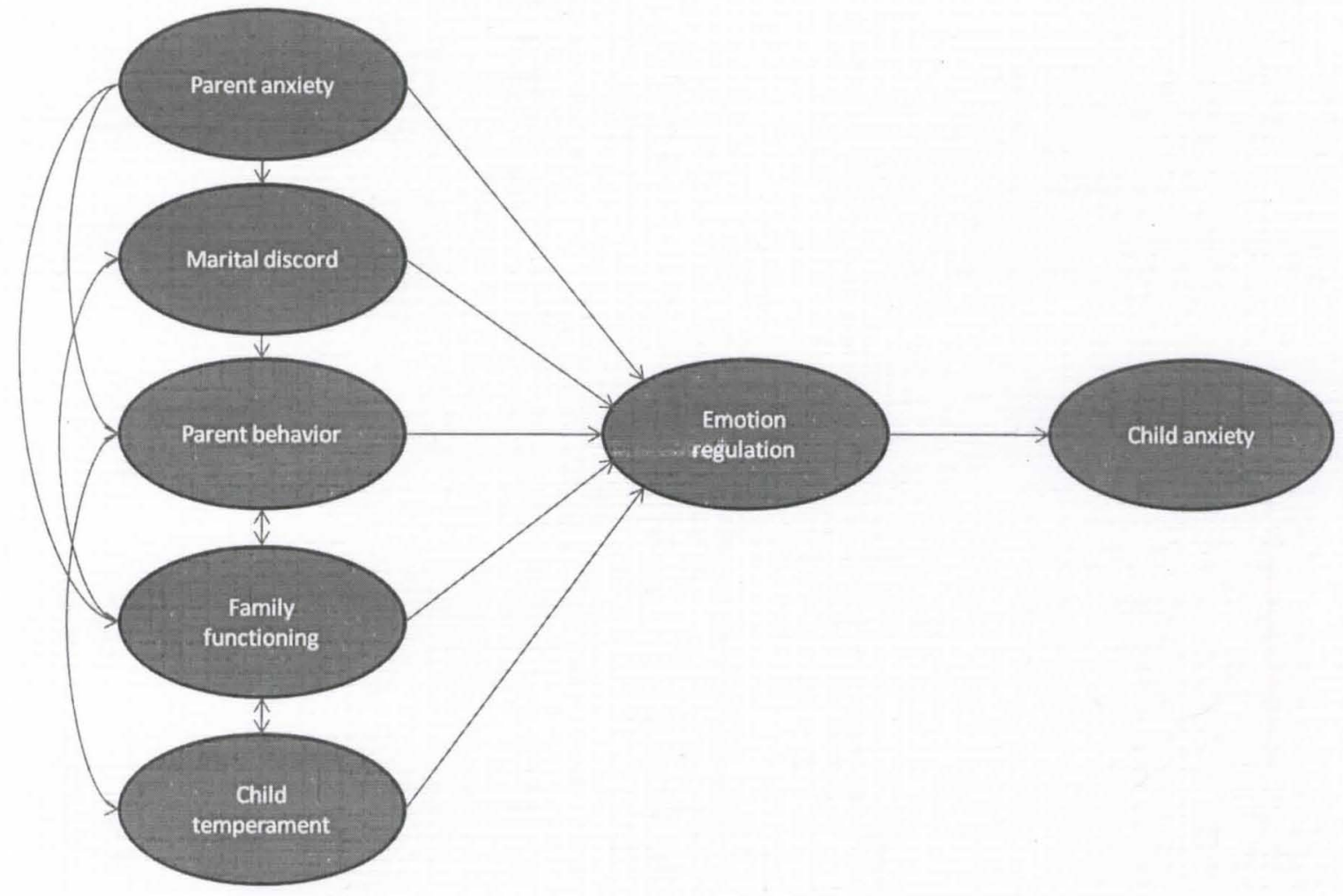

The current model illustrates the potential moderating role of parent and child variables on the development of child emotion regulation and the mediational role of child emotion regulation on the development of child anxiety. The model starts with the transactional relationship between parenting behaviors, child temperament, parent psychopathology, and family environment. These factors interact to moderate the development of child emotion regulation. The development of emotion regulation, in turn, mediates the relationship between these variables and the development of child anxiety. Depending on the confluence of vulnerability, risk, and protective factors at any given point in development the acquisition of emotion regulation skills and their relationship to anxiety may represent a resilience process.

The current study represents the first step in testing the hypothesized model and examines emotion regulation as a mediator of the relationship between child, parent, and 
family factors and child anxiety symptoms. Based on the reviewed literature one child variable (temperament), two parent variables (anxiety and parenting behavior), and two family variables (family functioning and marital discord) are used. The current study was completed using a cross-sectional design with school aged children 7-10 years of age. Focusing on children 7-10 years of age limits the potential impact of differences in neural development as most children in this age range have likely developed the neural attentional systems contributing to the temperamental quality of EC (Derryberry \& Rothbart, 1997; Kopp, 1982; Posner \& Rothbart, 2000). As such, differences in EC are less likely to be the result of maturational differences and more likely attributed to individual differences in temperamental traits. Additionally, even though peers are beginning to play a larger role, particularly in children at the top of this age range, family environment and parents are still important agents of socialization in this age group (Jakes \& DeBord, 2010).

Although there is empirical support for many of the main effect relationships outlined in the model, the larger mediational relationship between parent, child and family factors, emotion regulation, and child anxiety has not been tested in children. The aim of the current study was to test the hypothesized mediation model. The current study tested several related hypotheses across three levels of analysis. At the first level, to support the inclusion of each of the child, parent, and family factors in the larger model, the relationships between these factors were examined. Next, to establish which variables were tested for indirect relationships with child anxiety, the relationships between family, child and parent factors and child anxiety and emotion regulation were examined. Finally, at the third level, the potential mediating role of child emotion regulation was explored. 


\section{Hypotheses}

Level 1: Examination of the relationships between child, parent, and family factors.

- Hypothesis one: Child temperament will correlate with family functioning and parent behavior.

- Hypothesis two: Parent anxiety symptoms will predict marital discord, family functioning, and parent behavior.

- Hypothesis three: Pearson's product moment correlations will be used to test the hypothesis that measures of family functioning will correlate with measures of marital discord.

- Hypothesis four: Marital discord and family functioning will predict parenting behavior.

Level 2: Examination of the relationships between child, parent, and family factors, child emotion regulation and child anxiety.

- Hypothesis five: Child temperament, parenting, parent anxiety symptoms, family functioning, and marital discord will correlate with child emotion regulation.

- Hypothesis six: Child temperament, parenting, parent anxiety symptoms, marital discord, family functioning, and child emotion regulation will be correlated with child anxiety symptoms.

\section{Level 3: Examination of child emotion regulation as a mediator of the} relationship between child, parent, and family factors and child anxiety.

- Hypothesis seven: Child emotion regulation will mediate the relationship 
between child temperament, parenting, marital discord, and family functioning and child anxiety symptoms. 


\section{METHOD}

\section{Recruitment}

Participating families were recruited through informational flyers distributed at doctors' offices and places of business, and through letters of interest sent home with children through schools and churches. Recruiting took place in three geographic areas: Louisville, KY, Anderson, IN, and Belmont, MA.

To calculate the required sample size, G*Power 3.1 (Faul, Erdfelder, Lang, \& Bauchner, 2007) was used. To detect a moderate effect size (.30) with a power of (.80) for correlation analysis a sample size of 64 is needed. To detect a moderate effect size (.35) with a power of (.80) for regression analysis examining mediation with two predictor variables a sample size of 70 is needed. However, Fritz and MacKinnon (2007) suggest a sample size of 100-124 to detect a mediated effect depending on the statistical approach being used. As a result, a minimum sample size of 100 is needed for the current study. The observed power for mediation analysis in the current study ranged from .77 and .93 .

\section{Procedure}

Parent and child dyads were recruited for the current study. Dyads consisted of one parent and one biological child between the ages of 7-10 years with no known developmental delays. Dyads were asked to complete several self-report measures of child temperament, family environment, child emotion regulation, parenting, anxiety and 
depression. Parents were asked to complete a total of six report forms taking approximately 60 minutes to complete. Children were asked to complete one report form on anxiety taking approximately $15-20$ minutes to complete.

Children within the study age range recruited through schools or churches were given a letter of interest to take home to their parents. The letter provided a brief description of the study and potential benefits, and asked parents to indicate interest in receiving more information. Children of interested families were then given a study packet from their school or church. Parents and children were asked to complete the report forms at their own pace over the course of one week and return them in a sealed envelope, which was provided, with their child to school or church.

Families recruited from community flyers contacted the lab or local graduate research assistant for additional information and a study packet was sent home via mail. The packets included a letter to the parent(s) explaining the purpose of the study, parent and child measures for that data collection period, and the informed consent and assent documents. Once completed families were asked to send packets back to the lab or local graduate research assistant in the self-addressed stamped envelope provided.

In both instances, parents were asked to review the consent document and the assent document with their child and encouraged to contact the lab with any concerns or questions.

\section{Participants}

Participants were 100 parent-child dyads with children ages 7-10 years. Families were recruited across three geographic areas: Louisville, KY $(n=16)$, Anderson, $\mathbb{I N}(n=$ $42)$, and Belmont, MA $(n=42)$. Children in the study were $61 \%$ male $(n=61)$. The 
average age was 8.31 years $(S D=1.12)$. The study sample consisted of $31 \% 7$ year olds, $27 \% 8$ year olds, $22 \% 9$ year olds, and $20 \% 10$ year olds. Parents in the study were $90 \%$ female $(n=90)$. The average age was 39.45 years $(S D=6.57)$. Sixty-seven percent $(n=$ 67) of the parents had completed at least a bachelor's degree and 52\% $(n=52)$ were employed full-time. Ninety percent $(n=90)$ of the parents reported being married and $76 \%(n=76)$ reported a gross household income of over $\$ 60,000$. Thirty-three percent ( $n$ $=33)$ of the families identified as Catholic and $38 \%(n=38)$ identified as Protestant. The ethnic composition of families participating in the study was primarily European American (94\%), 1\% African American, 2\% Asian American, 1\% Hispanic American, and $2 \%$ identified as Other.

\section{Measures}

\section{Parent report measures.}

The Temperament in Middle Childhood Questionnaire - Parent Form (TMCQ) (Simonds \& Rothbart, 2004). The TMCQ is a paper-and-pencil parent-report of temperament in children 7-10 years of age. The TMCQ was based on the Children's Behavior Questionnaire (CBQ; Rothbart, Ahadi, Hersey, \& Fisher, 2001), a parent-report measure of temperament for children 3-7 years old. The TMCQ contains 16 scales comprised of 157 items and requires 20-25 minutes to complete. Internal consistency for the parentreport range from .63 to .90 , and factor analysis shows a four factor solutions with the factors Negative Affect, Effortful Control, Surgency, and Sociability (Simonds \& Rothbart, 2004). The current study used the Effortful Control (EC) and Negative Affect (NA) factors as measures of the child temperament. Higher scores on NA indicate more 
difficulty with negative emotions and lower scores on EC indicate more difficulty utilizing attentional resources.

Behavior Rating Inventory of Executive Function - Parent Version (BRIEF) (Gioia, Isquith, Guy, \& Kenworthy, 2000). The BRIEF, a questionnaire for parents of children 518 years old, is comprised of 86 items which measure different aspects of executive functioning. The measure includes eight subscales Inhibit, Shift, Emotional Control, Initiate, Working Memory, Plan/Organize, Organization of Materials, and Monitor, two validity scales Inconsistency and Negativity, and three index scores Behavioral Regulation, Metacognition, and Global Executive Composite. The measure has high internal consistency (ranging from .80-.98), good test-retest reliability (ranging from .76.88), and good inter-rater reliability (Gioia et al., 2000). The Behavior Regulation index (BRI) was used as a measure of child emotion regulation for the current study. Higher scores on the BRI indicate more difficulty with emotion regulation.

\section{Parent self-report measures.}

Beck Anxiety Inventory (BAI) (Beck \& Steer, 1990). The BAI is a widely used selfreport for assessing anxiety symptoms in adults. The measure includes 21 items rated on a scale of $0-3$. The BAI has been found to have high internal consistency and test-retest reliability and excellent concurrent and discriminate validity (Beck, Epstein, Brown, \& Steer, 1988; Hewitt \& Norton, 1993). The total score of the BAI was used as the measure of parent anxiety symptoms in the current study with higher scores indicating more anxiety.

Parenting Dimensions Inventory - Short Version (PDI-S) (Power, 2002). The PDI-S consists of 27 items comprising 6 subscales assessing parent support (Nurturance), parent 
Control (amount of control and type of control), and parent structure (inconsistency, following through on discipline, and organization). The PDI-S is a parent report measure for use with children 3-12 years of age. The measure includes a series of descriptive statements on six-point likert scales for assessing parental nurturance, inconsistency, and following through on discipline. Finally, there are a series of opposing statements for which parents must choose the statement that they agree with most for assessing amount of control, and five disciplinary situations where parents indicate on four-point Likert scales how likely it is that they would use different types of discipline. The measure has acceptable test-retest reliability and internal consistencies ranging from $.66-.92$. The Nurturance and Control subscales were used as measures of parenting behavior for the current study. Higher scores indicate more nurturance and greater parental control.

\section{Family measures.}

Family Assessment Device (FAD) (Epstein, Baldwin, \& Bishop, 1983). The FAD is a 60 item self-report measure of family functioning that contains six theoretically derived subscales: problem solving, communication, roles, affective responsiveness, affective involvement, and behavior control. There is an additional 12 item subscale, general functioning that provides a global measure of family health. Test-retest reliabiiity and internal consistencies are strong (Epstein et al., 1983; Miller, Epstein, Bishop, \& Keitner, 1985). The General Functioning subscale was used as the measure of family functioning for the current study with higher scores indicating lower family functioning. Marital Adjustment Test (MAT) (Locke \& Wallace, 1959). The MAT is a 15 item assessment of marital satisfaction and disagreement. The measure is widely used for research and clinical purposes. It has excellent reliability (split-half $=.90$ ) and has been 
shown to discriminate between non-distressed couples and couples with known marital difficulties (Locke \& Wallace, 1959). The total score on the MAT was used as the measure of marital discord for the current study with higher scores indicating increased marital discord.

\section{Child self-report measures.}

Beck Anxiety Inventory-Youth (BAI-Y) (Beck, Beck, \& Jolly, 2001; Steer, Kumar, Beck, \& Beck, 2001). The BAI-Y is a self-report measure of anxiety in youth ages 7-14. The measure included 20 items. Items are written at a second grade level and are rated on a 4-point Likert scale. The inventory has high internal consistency (>.84) and testretest reliability, construct validity, and convergent validity in both clinical and nonclinical samples. The inventory was constructed to address criteria listed in the American Psychiatric Association Diagnostic and Statistical Manual of Mental Disorders (4th edition) (1994) for anxiety. The total score of the BAI-Y was used as the measure of child anxiety for the current study with higher scores indicating more anxiety. 


\section{RESULTS}

\section{Examination of study measures}

The final study sample consisted of 90 dyads with a complete data set. Six parents did not return a completed TMCQ and 4 parents identified as single or divorced and did not complete the MAT. Of the 100 returned research packets, there were a total of 34 missing items or less than $1 \%$ of the total items ( 100 participants $x 413$ items per packets $=41300$ ). To increase power for statistical analysis missing data were replaced using hot deck imputation (Myers, 2011). Hot deck imputation creates a "deck" of possible "donor" participants based on criteria chosen by the researcher. The program then randomly assigns a value from the group of possible donor participants to replace the missing data points (Myers, 2011). In the current study, ethnicity, collection site, and gender were used as criteria to identify possible donor participants for the hot deck procedure.

Psychometrics for study measures were assessed by examining internal consistency with Cronbach coefficient alphas. Alphas of .70 or greater were considered acceptable. Descriptive statistics and Cronbach coefficient alphas for study measures are presented in Table 1. Overall, study variables indicated acceptable internal consistency with a few exceptions.

The TMCQ factors of NA and EC were used as measures of child temperament in the current study. Cronbach coefficient alphas ranged from $.65-.88$ for the subscales comprising the two factors. The internal consistency for the subscales of Discomfort, 
Fear, and Low Intensity Pleasure were lower than expected but were within the published range for the measure and were used in the calculation of NA and EC. Additionally, the TMCQ subscale of Perceptual Sensitivity had a lower than expected coefficient alpha of .14. As a result, the subscale was removed in the calculation of the EC subscale. As the EC factor is a collection of conceptually related but independent subscales, the absence of the Perceptual Sensitivity subscale should not impact the validity of the overall factor. The PDI subscale of Control had a lower than expected coefficient alpha of .43 . The Control subscale of the PDI was not used in further analysis. A new subscale named Negative Control was created by combining the PDI-S control type subscales of Physical Punishment and Scolding. The overall proportion was then calculated by dividing the combined mean of Physical Punishment and Scolding by the mean of all control types (Letting Go, Material/Social Consequences, Reasoning, Reminding, physical punishment and scolding). The Negative Control variable received an alpha coefficient of .86 . 
Table 1.

Descriptive Statistics for Study Measures.

\begin{tabular}{lll}
\hline Measure & Mean (SD) & Cronbach $\alpha$ \\
\hline Beck Anxiety Inventory - Youth & $12.12(7.15)$ & .87 \\
Beck Anxiety Inventory - II & $5.07(5.38)$ & .86 \\
Family Assessment Device - General & $1.55(.37)$ & .87 \\
Functioning subscale & $116.52(24.29)$ & .77 \\
Marital Adjustment Test & $31.65(3.49)$ & .71 \\
Parenting Dimensions Inventory - & $.62(.25)$ & .86 \\
Nurturance subscale & $2.50(.49)$ & \\
Parenting Dimensions Inventory - & & \\
Negative Control subscale & & .81 \\
Temperament in Middle Childhood & & .70 \\
Questionnaire - Negative Affect factor & & .68 \\
Anger & & .79 \\
Discomfort & & .77 \\
Fear & & .90 \\
Sadness & & .96 \\
Soothability & $3.60(.43)$ & .88 \\
Temperament in Middle Childhood & & .68 \\
Questionnaire - Effortful Control factor & & \\
Attention & & \\
Inhibitory Control & & \\
Low Intensity Pleasure & & \\
Perceptual Sensitivity & & .96 \\
BRIEF Behavior Regulation index & & \\
Emotion Control & & \\
Inhibit & & \\
Shift & & \\
\hline & & \\
\hline
\end{tabular}

* Not used in calculation of factor 
Finally, despite the relatively narrow age range used in the current study, child age was examined as a possible covariate. Children were split into four groups based on age $(7,8,9$, and 10) and an analysis of variance was conducted with the main outcome measures child anxiety (BAI-Y) and emotion regulation (BRI) as dependent variables. No significant differences were found.

\section{Examination of statistical assumptions}

Normality of the data distribution for study variables was examined using histograms, Q-Q plots. Skewness and kurtosis values were also used and z-score values greater than 2.58 were considered significant and would require transformation (Field, 2005). Visual inspection of histograms and Q-Q plots indicated possible non-normal distributions for the MAT, FAD, BAI, and BAI-Y. Log transformations were performed on the measures listed above and normality of the distributions was re-assessed. Skewness z-scores ranged from -1.54 to .50 and kurtosis z-scores ranged from -.83 to 2.40 and histogram and Q-Q plots improved suggesting normal distributions for the FAD, BAI, and BAI-Y. Although skewness and kurtosis z-scores were within normal ranges, MAT Q-Q plot continued to suggest a non-normal distribution. The first question on the MAT asks participants to rate their overall satisfaction with their marriage based on a 0 (Very Unhappy) to 35 (Perfectly Happy) scale. Based on research suggesting that the first item on the MAT is as reliable a measure of marital discord as the total score (Cross \& Sharpley, 1981), the decision was made to use the first item on the scale as the measure of marital discord in the current study. The items skewness z-score of -.69 and kurtosis zscore of .60 fell within the expected ranges and visual inspection of the histogram and QQ plots indicated a normal distribution. 


\section{Hypothesis testing}

\section{Level 1: examination of the relationships between child, parent, and family}

\section{factors.}

Hypothesis one: It was hypothesized that child temperament would correlate with measures of family functioning and parent behavior. More specifically the follow relationships were hypothesized:

- Scores on the TMCQ EC subscale would be negatively correlated with scores on the FAD General Functioning subscale and scores on the TMCQ NA subscale would be positively correlated with scores on the FAD General Functioning subscale.

- Scores in the PDI-S Nurturance subscale would be positively correlated with scores on the TMCQ EC subscale and negatively correlated with scores on the TMCQ NA subscale.

- Scores the PDI-S Negative Control subscale would be negatively correlated with scores on the TMCQ EC subscale and positively correlated with scores on the TMCQ NA subscale.

Child NA (TMCQ) correlated negatively with family functioning (FAD), $r(94)=$ $.32, p=.002$, and parent nurturing behavior (PDI-S), $r(93)=-.23, p=.026$. The correlation between Child EC (TMCQ) and parent nurturing behavior (PDI-S) approached significance, $r(93)=.20, p=.052$. There were no significant relationships between child EC (TMCQ) and parent negative control behavior (PDI-S) or family functioning (FAD). Nor was there a significant association between child NA (TMCQ) 
and parent negative control behaviors (PDI-S). See Table 2 for a list of correlation results.

Table 2.

Hypothesis One Correlation Results.

\begin{tabular}{|c|c|c|c|c|c|}
\hline Measure & FAD & Nurture & Control & $\mathrm{NA}$ & $\mathrm{EC}$ \\
\hline \multicolumn{6}{|l|}{ FAD } \\
\hline $\mathrm{n}$ & & & & & \\
\hline Nurture & $-.37 * *$ & & & & \\
\hline $\mathrm{n}$ & 99 & & & & \\
\hline Control & .10 & $-.28 * *$ & & & \\
\hline $\mathrm{n}$ & 100 & 99 & & & \\
\hline NA & $.32^{* *}$ & $-.23^{*}$ & .19 & & \\
\hline $\mathrm{n}$ & 94 & 99 & 94 & & \\
\hline EC & -.12 & $.20 *$ & -.09 & $-.31 * *$ & \\
\hline $\mathrm{n}$ & 94 & 93 & 94 & 94 & \\
\hline
\end{tabular}

Note: $\mathrm{FAD}=$ Family Assessment Device General Functioning subscale, Nurture $=$ Parenting Dimensions Inventory Nurturance subscale, Control = Parenting Dimensions Inventory Proportion of Negative Control subscale, NA = TMCQ Negative Affect factor, $\mathrm{EC}=\mathrm{TMCQ}$ Effortful Control factor ${ }^{*} p<.05,{ }^{* *} p<.01$

Hypothesis two: It was hypothesized that measures of parent anxiety symptoms would predict scores on measures of marital discord, family functioning, and parent behavior. Three independent regression equations were created using parent BAI scores as the independent variable and scores on the MAT, FAD, and PDI-S as dependent variables. It was hypothesized that increased scores on the BAĨ would predict increased total scores on the MAT, increased scores on the General Functioning subscale of the FAD, and 
increased scores on the Negative Control subscale and decreased scores on the Nurturance subscale of the PDI-S.

Regression analysis indicated a statistically significant model with lower parent anxiety symptoms (BAI) predicting lower parent negative control behavior (PDI-S), $F(1$, $98)=11.02, p=.001$. The model explained approximately $10 \%$ of the variance in parent negative control behavior. Parent anxiety symptoms did not predict marital discord (MAT), family functioning (FAD), or parent nurturing behavior (PDI-S). See Table 3 for a list of regression results

Table 3.

Hypothesis Two Regression Results.

\begin{tabular}{lllll}
\hline Measure & $\mathrm{t}$ & $\beta$ & $p$ value & $\mathrm{R}^{2}$ \\
\hline MAT & .05 & .005 & .96 & .00 \\
FAD & 1.46 & .15 & .15 & .02 \\
PDI-Nurturing & -.67 & -.07 & .51 & .01 \\
PDI - Negative Control & 3.32 & .32 & .001 & .10 \\
&. & & & \\
\hline
\end{tabular}

Notes: MAT - Marital Adjustment Test, FAD - Family Assessment Device, PDI Nurturing - Parenting Dimensions Inventory Nurturing subscale, PDI Negative Control Parenting Dimensions Inventory Negative Control subscale

To assess the generalizability of the model assumptions were examined and scatterplots showed roughly linear relationships between variables. Distribution of residual values did not indicate problems with homoscedasticity, and examination of Cook's and Mahalanobis distance values did not indicate any multivariate outliers with all values under the cut point of 15 (Field, 2005). The VIF (1.0) and tolerance (1.0) 
values were within normal limits suggesting no problems with multicollinearity, and graphs of the standardized residuals indicated that the model was normally distributed. Hypothesis three: It was hypothesized that measures of family functioning would be correlated with measures of marital discord. More specifically, total scores on the MAT would be positively correlated with scores on the General Functioning subscale of the FAD.

Marital discord (MAT) was significantly correlated with the family functioning (FAD), $r(96)=-.45, p<.001$.

Hypothesis four: It was hypothesized that measures of marital discord and family functioning would predict measures of parenting behavior.

- First, total scores on the MAT were entered as the independent variable and the Negative Control and Nurturance subscales of the PDI-S were entered as dependent variables. Lower total scores on the MAT were hypothesized to predict decreased scores on the PDI-S Negative Control subscale and increased scores on PDI-S Nurturance subscale.

- Next, the FAD General Functioning scores were entered as the independent variable and the scores from the Negative Control and Nurturance subscales of the PDI-S were entered as dependent variables. Higher scores on the General Functioning subscale of the FAD would predict increased scores on the PDI-S Negative Control subscale and decreased scores on PDI-S Nurturance subscale.

Regression analysis showed a statistically significant model with increased family functioning $(\mathrm{FAD})$ predicting greater parent nurturing behavior (PDI-S), $F(1,97)=$ 
$14.08, p<.001$. These results indicate that increased family functioning predicts increased parent nurturing behavior with family functioning explaining approximately $13 \%$ of the variance in parent nurturing behavior. However, family functioning (FAD) did not predict parent negative control behavior (PDI-S), and marital discord (MAT) did not predict parenting behavior (PDI-S). See Table 4 for a list of regression results. Table 4.

Hypothesis Four Regression Results.

\begin{tabular}{llllll}
\hline IV & DV & $\mathbf{t}$ & $\beta$ & $p$ value & $\mathrm{R}^{2}$ \\
\hline MAT & & & & & \\
& PDI-Nurturing & -.13 & -.01 & .90 & .00 \\
& PDI - Negative Control & .26 & .03 & .79 & .001
\end{tabular}

FAD

\begin{tabular}{lllll} 
PDI-Nurturing & -3.75 & -.36 & $<.001$ & .13 \\
PDI - Negative Control & .26 & .03 & .80 & .001 \\
\hline
\end{tabular}

Notes: MAT - Marital Adjustment Test, FAD - Family Assessment Device, PDI Nurturing - Parenting Dimensions Inventory Nurturing subscale, PDI Negative Control Parenting Dimensions Inventory Negative Control subscale

Again, to assess the generalizability of the model, assumptions were examined and scatterplots showed roughly linear relationships between variables. Distribution of residual values did not indicate problems with homoscedasticity, and examination of Cook's and Mahalanobis distance values did not indicate any multivariate outliers with all values under the cut point of 15 (Field, 2005). The VIF (1.0) and tolerance (1.0) values were within normal limits suggesting ne problems with multicollinearity, and graphs of the standardized residuals indicated that the model was normally distributed. 


\section{Level 2: Examination of the relationships between child, parent, and family}

\section{factors, child emotion regulation and child anxiety.}

Hypothesis five: It was hypothesized that scores on measures of child temperament, parenting, parent anxiety symptoms, family functioning, and marital discord would correlate with measures of child emotion regulation. More specifically, the following relationships were hypothesized:

- Scores on the TMCQ EC subscale would be negatively correlated with scores on the BRI of the BRIEF and scores on the TMCQ NA subscale would be positively correlated with scores on the BRI of the BRIEF.

- Scores in the Nurturance subscale of the PDI-S would be negatively correlated with scores on the BRI of the BRIEF and the Negative Control subscale of the PDI-S would be positively correlated with scores on the BRI of the BRIEF.

- Total scores on the MAT would be positively correlated with scores on the BRI of the BRIEF and scores on the General Functioning subscale of the FAD would be positively correlated with scores on the BRI of the BRIEF.

- Scores on the BAI would be positively correlated with scores on the BRI of the BRIEF.

Significant positive correlations were found between child emotion regulation (BRIEF) and child NA (TMCQ), $r(94)=.66, p<.001$, family functioning (FAD), $r$ $(100)=.30, p=.002$, and parent anxiety symptoms $(\mathrm{BAI}), r(100)=.29, p=.004$. Child emotion regulation (BRIEF) and child EC (TMCQ) were negatively associated, $r(94)=$ $.40, p<.001$. 
No significant relationships were found between parenting behavior (PDI-S) or marital discord (MAT) and child emotion regulation (BRIEF). See Table 5 for a list of correlation results.

Table 5 .

Hypothesis Five Correlation Results.

\begin{tabular}{llllllll}
\hline Measure & BAI & FAD & MAT & Nurture & Control & NA & EC \\
\hline BAI & & & & & & & \\
FAD & .15 & & & & & & \\
$\mathrm{n}$ & 100 & & & & & & \\
MAT & -.03 & $-.45^{* *}$ & & & & & \\
$\mathrm{n}$ & 96 & 96 & & & & & \\
Nurture & -.07 & $-.37^{* *}$ & -.05 & & & & \\
$\mathrm{n}$ & 99 & 99 & 95 & & & & \\
Control & $.32^{* *}$ & .10 & .04 & $-.28^{* *}$ & & & \\
$\mathrm{n}$ & 100 & 100 & 96 & 99 & & & \\
NA & $.39 * *$ & $.32^{* *}$ & -.005 & $-.23^{*}$ & .19 & & \\
$\mathrm{n}$ & 94 & 94 & 90 & 99 & 94 & & \\
EC & -.04 & -.12 & .02 & $.20^{*}$ & -.09 & $-.31^{* *}$ & \\
$\mathrm{n}$ & 94 & 94 & 90 & 93 & 94 & 94 & \\
BRI & $.29 * *$ & $.30^{* *}$ & -.10 & -.18 & .16 & $.66^{* *}$ & $-.40^{* *}$ \\
$\mathrm{n}$ & 100 & 100 & 96 & 99 & 100 & 94 & 94 \\
\hline $\mathrm{N}$ & & & & & & & \\
\hline
\end{tabular}

Note: BAI = Beck Anxiety Inventory II, FAD = Family Assessment Device General Functioning subscale, MAT $=$ Locke Wallace Marital Adjustment Test, Nurture = Parenting Dimensions Inventory Nurturance subscale, Control = Parenting Dimensions Inventory Proportion of Negative Control subscale, NA = TMCQ Negative Affect factor, $\mathrm{EC}=\mathrm{TMCQ}$ Effortful Control factor, BRI = BRIEF Behavior Regulation index. ${ }^{*} p<.05$, $*^{* *} p<.01$ 
Hypothesis six: It was hypothesized that measures of child temperament, parenting, parent anxiety symptoms, marital discord, family functioning, and child emotion regulation would be correlated with child anxiety symptoms. More specifically, the following relationships were hypothsized:

- Scores on the TMCQ NA subscale would be positively correlated with total scores on the BAI-Y and scores on the TMCQ EC subscale would be negatively correlated with total scores on the BAI-Y.

- Total scores on the MAT would be positively correlated with total scores on the BAI-Y and scores on the General Functioning subscale of the FAD would be positively correlated with total scores on the BAI-Y.

- Scores on the PDI-S Negative Control subscale would be positively correlated with total scores on the BAI-Y and scores on the PDI-S Nurturance subscale would be negatively correlated with total scores on the BAI-Y.

- Total scores on the BAI would be positively correlated with total scores on the BAI-Y.

- Scores on the BRI of the BRIEF would be positively correlated with total scores on the BAI-Y.

Child anxiety (BAI-Y) correlated positively with child NA (TMCQ), $r(94)=.36$, $p<.001$, parent negative control behavior (PDI-S), $r(100)=.27, p=.008$, parent anxiety symptoms (BAI), $r(100)=.30, p=.003$, and child emotion regulation (BRIEF), $r(100)$ $=.28, p=.005$. 
No significant relationships were found between child anxiety (BAI-Y) and child EC factor (TMCQ), parent nurturing behavior (PDI-S), marital discord (MAT), or family functioning (FAD). See Table 6 for a list of correlation results.

Table 6.

Hypothesis Six Correlation Results.

\begin{tabular}{|c|c|c|c|c|c|c|c|c|}
\hline Measure & BAI & BAI-Y & FAD & MAT & Nurture & Control & $\mathrm{NA}$ & $\overline{\mathrm{EC}}$ \\
\hline \multicolumn{9}{|l|}{$\mathrm{BAI}$} \\
\hline BAI-Y & $.30^{* *}$ & & & & & & & \\
\hline $\mathrm{n}$ & 100 & & & & & & & \\
\hline FAD & .15 & .15 & & & & & & \\
\hline $\mathrm{n}$ & 100 & 100 & & & & & & \\
\hline MAT & -.03 & -.05 & $-.45 * *$ & & & & & \\
\hline $\mathrm{n}$ & 96 & 96 & 96 & & & & & \\
\hline Nurture & -.07 & -.04 & $-.37 * *$ & -.05 & & & & \\
\hline $\mathrm{n}$ & 99 & 99 & 99 & 95 & & & & \\
\hline Control & $.32 * *$ & $.27^{* *}$ & .10 & .04 & $-.28 * *$ & & & \\
\hline $\mathrm{n}$ & 100 & 100 & 100 & 96 & 99 & & & \\
\hline NA & $.39^{* *}$ & $.36^{* *}$ & $.32 * *$ & -.005 & $-.23^{*}$ & .19 & & \\
\hline $\mathrm{n}$ & 94 & 94 & 94 & 90 & 99 & 94 & & \\
\hline $\mathrm{EC}$ & -.04 & -.03 & -.12 & .02 & $.20^{*}$ & -.09 & $-.31 * *$ & \\
\hline $\mathrm{n}$ & 94 & 94 & 94 & 90 & 93 & 94 & 94 & \\
\hline BRI & $.29^{* *}$ & $.28^{* *}$ & $.30^{* *}$ & -.10 & -.18 & .16 & $.66^{* *}$ & $-.40^{* *}$ \\
\hline $\mathrm{n}$ & 100 & 100 & 100 & 96 & 99 & 100 & 94 & 94 \\
\hline
\end{tabular}


subscale, NA = TMCQ Negative Affect factor, EC = TMCQ Effortful Control factor, $\mathrm{BRI}=\mathrm{BRIEF}$ Behavior Regulation index. ${ }^{*} p<.05,{ }^{* *} p<.01$

\section{Level 3: Examination of child emotion regulation as a mediator of the relationship between child, parent, and family factors and child anxiety.}

Hypothesis seven: It was hypothesized that measures of child emotion regulation would mediate the relationship between measures of child temperament, parenting, marital discord, and family functioning and child anxiety symptoms.

The process outlined by Hayes (2009; in review-b) was used to test the mediation model. More specifically, the model was tested using an ordinary least squares based analytical path framework for estimating direct and indirect effects in simple and multiple mediator models. The SPSS macro PROCESS developed by Hayes (in review-a) was used to conduct the analysis. Traditional models of mediation (Baron \& Kenny, 1986) suggest that significant relationships must first exist between the independent variable (IV) and the dependent variable (DV), the IV and the mediator (M), and the $\mathrm{M}$ and the DV prior to testing for mediation; however, more contemporary models of mediation (Hayes, 2009) support the idea that indirect relationships between IVs and DVs through a mediator may exist in the absence of a significant association between the IV and the DV. As such, IVs will be considered for mediation analysis if a relationship exists between the IV and DV or IV and the M, even if a relationship between the IV and DV does not exist.

For the current model, BAI-Y was entered as the dependent variable, and the BRI of the BRIEF was entered as mediator variable. Child, parent, or family factors were examined if they were either related to the M (BRIEF BRI), the DV (BAI-Y) or both. 
Based on the above results, parent anxieiy symptoms (BAI), family functioning (FAD), child temperamental factors of EC and NA (TMCQ), and parenting negative control (PDI-S) were entered as IV in the current analysis. Results of the mediation analysis are presented in Table 7.

Mediation was assessed by directly testing the significance of the indirect effect of the IV on the DV through the M, which was quantified by the product of the effects of the IV on the M (a) and the effect of the M on the DV while controlling for the effect of the IV $(b)$. The current study used the bootstrap method outlined by Hayes (2009) for estimating indirect effects. A 95\% confidence interval (CI) was derived from estimates of the product of $a b$. Bootstrapping generates a sampling distribution of the indirect effect by using the obtained sample size as a representation of the larger population. The sampling distribution was generated 5000 times during the analysis and estimates of $a$ and $b$ were calculated, and confidence intervals determined (Hayes, 2009). The indirect effect was considered significant if the confidence interval did not include zero. 
Table 7.

Hypothesis Seven Indirect Effect Results.

\begin{tabular}{llllll}
\hline & $\begin{array}{l}\text { Effect of IV } \\
\text { on M (a) }\end{array}$ & $\begin{array}{l}\text { Effect of M } \\
\text { on DV }(\mathrm{b})\end{array}$ & $\begin{array}{l}\text { Direct } \\
\text { Effect }\left(\mathrm{c}^{\prime}\right)\end{array}$ & $\begin{array}{l}\text { Indirect Effect } \\
(\mathrm{a} \times \mathrm{b})\end{array}$ & \\
\hline $\begin{array}{l}\text { Independent } \\
\text { Variable }\end{array}$ & $\begin{array}{l}\text { Model } \\
\text { Coefficients }\end{array}$ & $\begin{array}{l}\text { Model } \\
\text { Coefficients }\end{array}$ & $\begin{array}{l}\text { Model } \\
\text { Coefficients }\end{array}$ & Effect & $95 \% \mathrm{CI}$ \\
\hline BAI & $13.62^{* *}$ & $.003^{*}$ & $.16^{*}$ & .04 & .007 to $.098^{*}$ \\
FAD GF & $29.12^{* *}$ & $.004^{*}$ & .12 & .10 & .027 to $.220^{*}$ \\
EC & $-8.42^{* *}$ & $.005^{* *}$ & .03 & -.04 & -.078 to $-.019^{*}$ \\
NA & $12.12^{* *}$ & .001 & $.08^{*}$ & .02 & -.030 to .064 \\
NC & 6.13 & $.003^{*}$ & $.12^{*}$ & .02 & -.003 to .065 \\
\hline
\end{tabular}

Notes: B.AI = Beck Anxiety Inventory II, FAD $=$ Family Assessment Device General Functioning subscale, NA = TMCQ Negative Affect factor, EC = TMCQ Effortful Control factor, $\mathrm{NC}=$ PDI-S Negative Control subscale. ${ }^{*} p<.05,{ }^{*} p<.01$

In the first model, adult anxiety (BAI) was entered as the IV, child emotion regulation (BRI) was input as the $\mathrm{M}$, and child anxiety (BAI-Y) was entered as the DV. Bootstrap resuils indicated child emotion regulation (BRI) was a significant mediator of the relationship between the parent (BAI) and child anxiety (BAI-Y). The total model accounted for approximately $13 \%$ of variance in child anxiety.

In the second model, family functioning (FAD) was entered as the IV, child ernotion regulation (BRI) was entered as the $\mathrm{M}$, and child anxiety (BAI-Y) was input as the DV. Bootstrap results indicated child emotion regulaion (BRI) was a significant mediator of the relationship berween family furctioning (FAD) and child anxiety (BAIY). The total model accounted for approximately $8 \%$ of variance in child anxiety.

In the third model, child EC (TMCQ) was input as the IV, child emotion regulation (BRI) was entered as the $M$, and child anxiety (BAI-Y) was entered as the DV. Bootstrap results indicated child emotion regulation (BRI) was a significant mediator of 
the relationship between the child EC (TMCQ) and child anxiety (BAI-Y). The total model accounted for approximately $9 \%$ of variance in child anxiety.

In the fourth model child NA (TMCQ) was entered as the IV, child emotion regulation (BRI) was entered as the $\mathrm{M}$, and child anxiety (BAI-Y) was entered as the DV. Bootstrap results indicated child emotion regulation (BRI) was not a significant mediator of the relationship between the child NA (TMCQ) and child anxiety (BAI-Y).

Finally, in the fifth model, parent negative control (PDI-S) was entered as the IV, child emotion regulation (BRI) was entered as the $\mathrm{M}$, and child anxiety (BAI-Y) was entered as the DV. Bootstrap results indicated child emotion regulation (BRI) was not a significant mediator of the relationship between the parent negative control (PDI-S) and child anxiety (BAI-Y).

\section{Exploratory Analyses}

\section{Mediation}

The current mediation analysis was conducted using Behavior Regulation index (BRI) of the BRIEF as the measure of child emotion regulation. However, the BRI consists of three subscales Emotion Control, Shift, and Inhibit. To further elucidate the relationship between variables, exploratory analyses were conducted examining the three subscales of the BRI as potential mediating variables. The same process for testing mediation and indirect relationships described above was used for the current analyses. See Table 8 for detailed results. 
Table 8.

Exploratory Analysis Indirect Effect Results.

\begin{tabular}{|c|c|c|c|c|c|c|}
\hline & & $\begin{array}{l}\text { Effect of } \\
\text { IV on M } \\
\text { (a) }\end{array}$ & $\begin{array}{l}\text { Effect of M } \\
\text { on DV (b) }\end{array}$ & $\begin{array}{l}\text { Direct } \\
\text { Effect (c') }\end{array}$ & \multicolumn{2}{|c|}{$\begin{array}{l}\text { Indirect Effect } \\
(\mathrm{a} \times \mathrm{b})\end{array}$} \\
\hline $\begin{array}{l}\text { Independent } \\
\text { Variable }\end{array}$ & $\mathrm{M}$ & $\begin{array}{l}\text { Model } \\
\text { Coeffici } \\
\text { ents }\end{array}$ & $\begin{array}{l}\text { Model } \\
\text { Coefficient } \\
\text { s }\end{array}$ & $\begin{array}{l}\text { Model } \\
\text { Coefficients }\end{array}$ & Effect & $95 \% \mathrm{CI}$ \\
\hline \multirow[t]{3}{*}{ BAI } & Emotion & $8.70^{* *}$ & $.007^{*}$ & .133 & .06 & $\begin{array}{l}.011 \text { to } \\
.142^{*}\end{array}$ \\
\hline & Shift & 2.80 & $.01^{*}$ & $.167^{* *}$ & .03 & $\begin{array}{l}.004 \text { to } \\
.074^{*}\end{array}$ \\
\hline & Inhibit & 2.13 & .002 & $190^{* *}$ & .004 & $\begin{array}{l}-.006 \text { to } \\
.038\end{array}$ \\
\hline \multirow[t]{3}{*}{ FAD GF } & Emotion & $13.69 * *$ & $.009 * *$ & .22 & .12 & $\begin{array}{l}.040 \text { to } \\
.263^{*}\end{array}$ \\
\hline & Shift & $11.10^{* *}$ & $.01^{*}$ & .11 & .12 & $\begin{array}{l}.034 \text { to } \\
.264^{*}\end{array}$ \\
\hline & Inhibit & 4.32 & .003 & .21 & .01 & $\begin{array}{l}-.010 \text { to } \\
.082\end{array}$ \\
\hline \multirow[t]{3}{*}{$\mathrm{EC}$} & Emotion & -1.63 & $.01 * *$ & .008 & -.02 & $\begin{array}{l}-.045 \text { to } \\
.002\end{array}$ \\
\hline & Shift & $-2.10 * *$ & $.01^{* *}$ & .02 & -.03 & $\begin{array}{l}-.061 \text { to }- \\
.007^{*}\end{array}$ \\
\hline & Inhibit & $-4.68 * *$ & .002 & .001 & -.01 & $\begin{array}{l}-.054 \text { to } \\
.023\end{array}$ \\
\hline \multirow[t]{3}{*}{$\mathrm{NA}$} & Emotion & $5.44 * *$ & .006 & .07 & .03 & $\begin{array}{l}-.012 \text { to } \\
.086\end{array}$ \\
\hline & Shift & $4.10^{* *}$ & .004 & $.08^{*}$ & .02 & $\begin{array}{l}-.026 \text { to } \\
.060\end{array}$ \\
\hline & Inhibit & $2.58^{* *}$ & -.002 & $.10^{* *}$ & -.004 & $\begin{array}{l}-.024 \text { to } \\
.010\end{array}$ \\
\hline \multirow[t]{3}{*}{$\mathrm{NC}$} & Emotion & .09 & $.31^{* *}$ & $.12^{*}$ & .03 & $\begin{array}{l}.002 \text { to } \\
.075^{*}\end{array}$ \\
\hline & Shift & 1.07 & $.01 * *$ & $.13^{*}$ & .01 & $\begin{array}{l}-.014 \text { to } \\
.050\end{array}$ \\
\hline & Inhibit & 2.04 & .002 & $.14^{*}$ & .004 & $\begin{array}{l}-.005 \text { to } \\
.031\end{array}$ \\
\hline
\end{tabular}

Notes: BA. $=$ Beck Anxiety Inventory $\overline{I I}$, FAD $=$ Family Assessment Device General Functioning subsca!e, NA = TMCQ Negative Affect factor, EC = TMCQ Effortful 
Control factor, Emotion = Emotion Control subscale of BRIEF, Shift $=$ Shift subscale of the BRIEF, Inhibit = Inhibit subscale of the BRIEF, NC $=$ PDI-S Negative Control subscale. ${ }^{*} p<.05, * * p<.01$

First, the Emotion Control subscale was explored as a potential mediator and five independent regression equations were created with child anxiety (BAI-Y) as the DV, Emotion Control as the mediator, and parent anxiety symptoms (BAI), child temperament (NA and EC), family functioning (FAD), and parent regative control (PDI-S) as independent variables. Bootstrap results indicated Emotion Control was a significant mediator of the relationship between parent anxiety symptoms (BAI) and child anxiety (BAI-Y). The total model accounted for approximately $13 \%$ of variance in child anxiety. Bootstrap results also indicated Emotion Control was a significant mediator of the relationship between family functioning (FAD) and child anxiety (BAI-Y). The total model accounted for approximately $10 \%$ of variance in child anxiety. Finally, bootstrap results indicated Emotion Control was a significant mediator of the relationship between parent negative control (PDI-S) and child anxiety (BAI-Y). The total model accounted for approximately $14 \%$ of variance in child anxiety. Emotion control was not a mediator of the relationship between child temperament (TMCQ) and child anxiety (BAI-Y). See Figure 2. 
Figure 2. Exploratory results with Emotion Control as mediator.

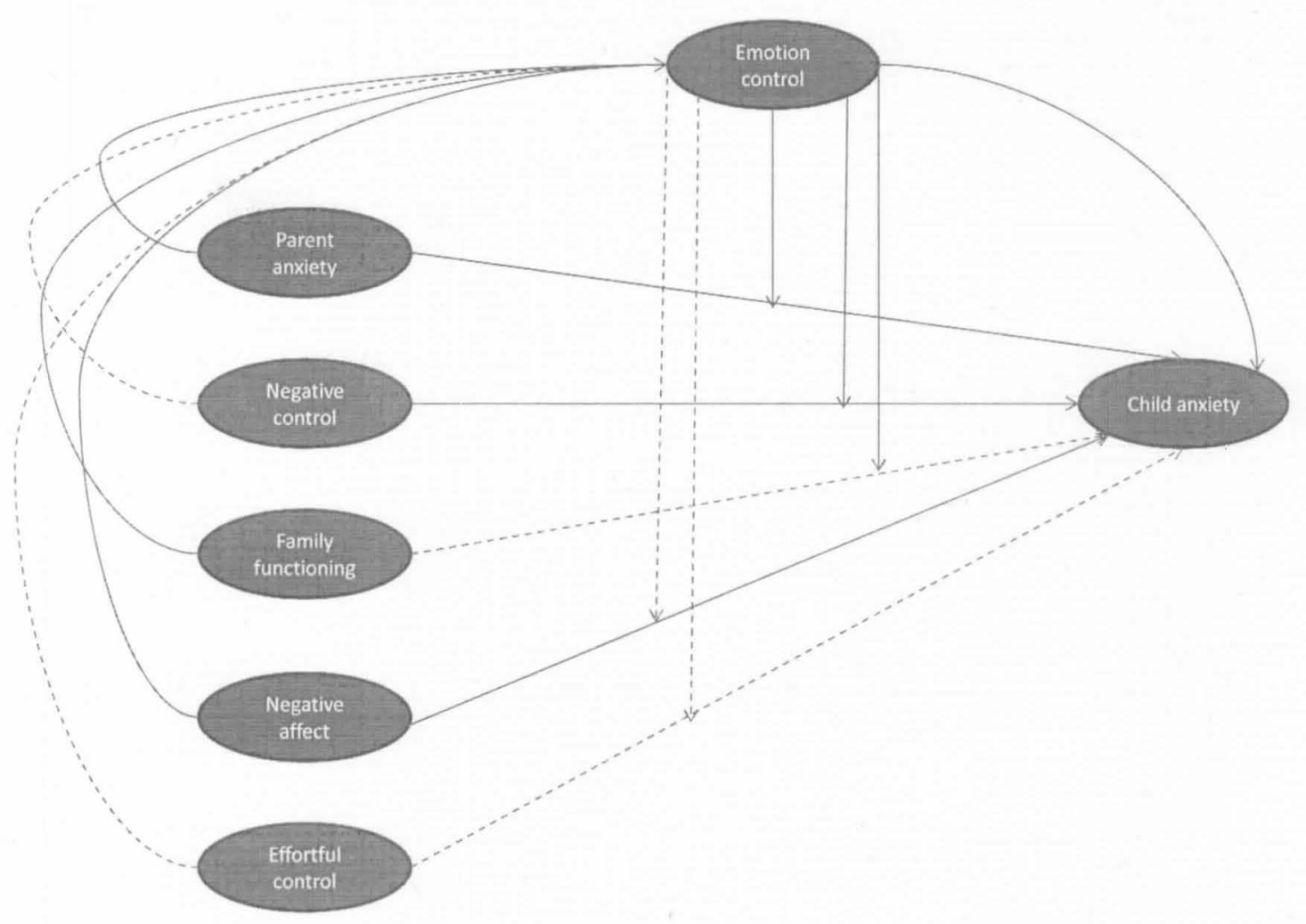

Note: Solid lines indicate significant relationships.

Next, the Shift subscale was explored as a potential mediator and five independent regression equations were created with child anxiety (BAI-Y) as the DV, Emotion Control as the mediator, and parent anxiety symptoms (BAI), child temperament (NA and EC), family functioning (FAD), and parent negative control (PDI-S) as independent variables. Bootstrap results indicated the Shift subscale was a significant mediator of the relationship between parent anxiety symptoms (BAI) and child anxiety (BAI-Y). The total model accounted for approximately $14 \%$ of variance in child anxiety. 
Bootstrap results indicated the Shift subscale was a significant mediator of the relationship between family functioning (FAD) and child anxiety (BAI-Y). The total model accounted for approximately $8 \%$ of variance in child anxiety. Bootstrap results also indicated the Shift subscale was a significant mediator of the relationship between the child temperament quaiity of EC (TMCQ) and child anxiety (BAI-Y). The total modei accounted for approximately $8 \%$ of variance in child anxiety. Shift did not mediate the relationship between the child temperament quality of NA (TMCQ) or parent negative control (PDI-S) and child anxiety (BAI-Y). See Figure 3. 
Figure 3. Exploratory results with Shift as mediator.

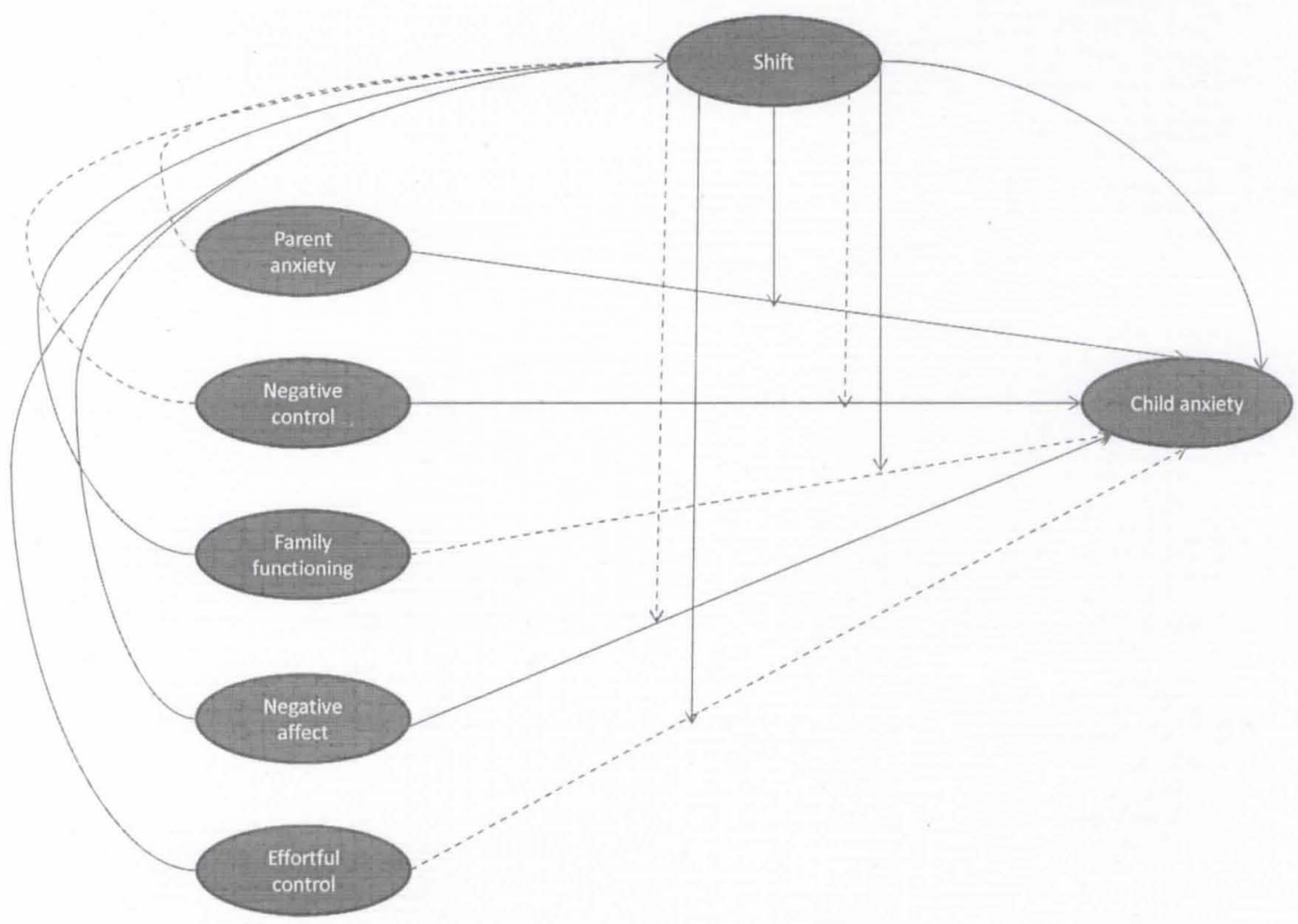

Note: Solid lines indicate significant relationships.

Finally, the regression models exploring the Inhibit subscale as a potential mediator between child anxiety (BAI-Y) and parent anxiety symptoms (BAI), family functioning (FAD), child temperament (TMCQ), and parent negative control (PDI-S) were not significant. See Figure 4. 
Figure 4. Exploratory results with Inhibit as mediator.

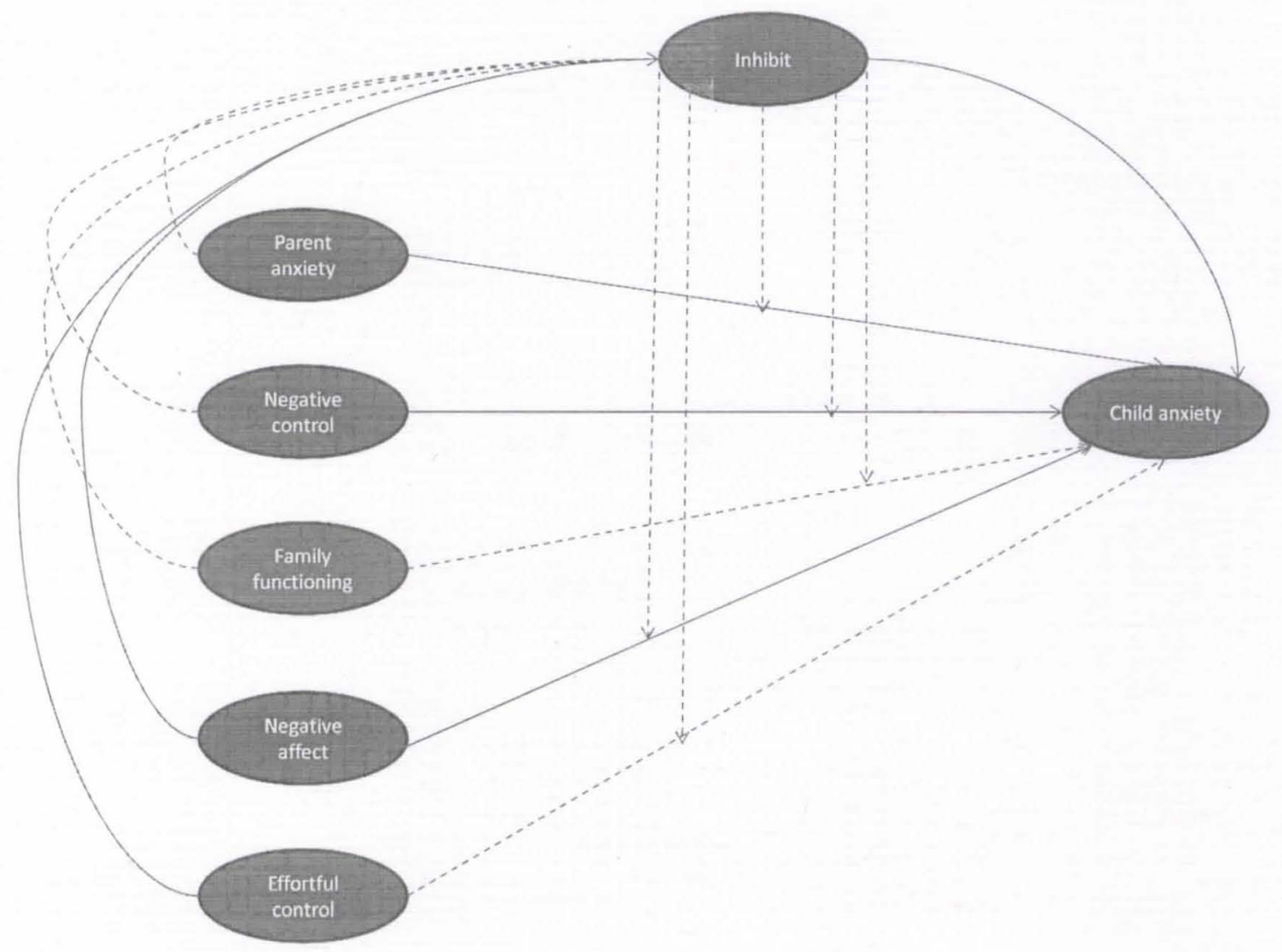

Note: Solid lines indicate significant relationships.

\section{Role of emotion regulation}

Due to the cross-sectional nature of the current study it is not possible to directly test how child emotion regulation might influence the development of child anxiety or how development of emotion regulation might be influenced by changes in child, parent, and family factors. To facilitate a better understanding of how emotion regulation might be influenced by study variables regression analysis was conducted using parent, child, and family variables as predictors of child emotion regulation in high and low anxious children. The study sample was split into high and low anxious groups using the BAI-Y mean as a cut point. Parent anxiety symptoms (BAI-Y), family functioning (FAD), child 
temperament (TMCQ), and parent negative control (PDI-S) were entered as IVs and child emotion regulation as measured by the Emotion Control subscale of the BRIEF was entered as the DV for both high and low anxious groups.

Regression analysis showed a statistically significant model with lower parent anxiety symptoms (BAI) predicting greater emotion regulation in both high anxious, $\beta=$ $.38, p=.007$, and low anxious, $\beta=.37, p=.008$, children (BAI-Y). These results indicate that parent anxiety symptoms influences child emotion regulation regardless of the current level of child anxiety.

The second regression model showed a statistically significant relationship with higher family functioning (FAD) predicting better emotion regulation in high anxious, $\beta$ $=.38, p=.007$, but not low anxious children (BAI-Y), $\beta=.15, p=.31$. These results suggest that family functioning has a greater impact on child emotion regulation in children with higher anxiety.

The third regression equation indicated a statistically significant relationship with lower child NA (TMCQ) predicting increased child emotion regulation in both low anxious, $\beta=.53, p<.001$, and high anxious, $\beta=.68, p<.001$, children (BAI-Y). These results also indicate that child NA influences child emotion regulation regardless of the level of child anxiety.

Neither child EC (TMCQ) or parent negative control (PDI-S) predicted child emotion regulation in high or low anxious children. Please see Table 9 for a summary of results. 
Table 9.

Exploratory Analysis Regression Results.

\begin{tabular}{|c|c|c|c|c|c|}
\hline Measure & $\begin{array}{l}\text { Anxiety } \\
\text { Group }\end{array}$ & $t$ & $\beta$ & $p$ value & $\mathrm{R}^{2}$ \\
\hline \multirow[t]{2}{*}{$\overline{\mathrm{BAI}}$} & High & 2.81 & .38 & .007 & .14 \\
\hline & Low & 2.78 & .37 & .008 & .14 \\
\hline \multirow[t]{2}{*}{ FAD } & High & 2.85 & .38 & .007 & .15 \\
\hline & Low & 1.03 & .15 & .30 & .02 \\
\hline \multirow[t]{2}{*}{$\mathrm{EC}$} & High & -1.55 & -.23 & .13 & .05 \\
\hline & Low & -1.03 & -.15 & .31 & .02 \\
\hline \multirow[t]{2}{*}{ NA } & High & 6.06 & .68 & $<.001$ & .46 \\
\hline & Low & 4.23 & .53 & $<.001$ & .28 \\
\hline \multirow[t]{2}{*}{$\mathrm{NC}$} & High & 1.01 & .16 & .28 & .03 \\
\hline & Low & .78 & .11 & .44 & .01 \\
\hline
\end{tabular}

Notes: BAI = Beck Anxiety Inventory II, FAD = Family Assessment Device General Functioning subscale, NA = TMCQ Negative Affect factor, EC = TMCQ Effortful Control factor, NC = PDI-S Negative Control subscale. 


\section{DISCUSSION}

The current study represents the first step in identifying a potential resilience process in children at risk for developing anxiety. The goal of the study was to test a model in which child emotion regulation mediated the relationship between parent, child, and family factors and child anxiety in a community sample of children ages $7-10$ years and their parents. The study tested several related hypotheses. First, relationships between parent anxiety symptoms, child temperament, parenting behavior, family environment, and marital relationship were examined. Next, the hypothesis that these parent, child and family variables were related to child emotion regulation and child anxiety was explored. Finally, the potential mediating role of child emotion regulation was explored. Additional exploratory analyses investigating specific subscales of the BRIEF BRI as mediators and potential differences in child emotion regulation in high and low anxious children were also considered. Results from the current study supported the inclusion of parent, child, and family factors in the larger model proposed earlier, and confirmed the role of child emotion regulation as a mediator of the relationships between several of the variables and child anxiety. The mediation of child anxiety through child emotion regulation might represent a resilience process in children at risk for developing anxiety. Results further substantiate the need to move away from simple direct relationships and consider more complex transactional models. Such models would allow for the examination of both risk and protective factors to understand how these variables might coalesce and impact the development of child emotion regulation and ultimately child anxiety. 


\section{Hypothesis Testing}

Relationships between parent, child, and family factors were examined to provide support for their inclusion in the larger conceptual model described previously (See figure 1). The first hypothesis that child temperament, specifically child NA and EC, would correlate with family functioning and parenting behavior was largely supported. Decreased child NA was associated with increased family functioning and decreased child NA was also related to increased parent nurturing behavior. Finally, increased child EC was associated with increased parent nurturing behavior. These results are consistent with current research (Kochanska \& Murray, 2000; Komsi et al., 2008) and support the potential influence that children have on their environment, as well as, the important role the environment may play in child socialization and development. The relationships between child temperament and parenting behavior and family environment are likely transactional ones in which child temperament influences parenting behavior and family functioning and child temperament is influenced by parenting and the quality of the family environment. It is this transactional process between child temperament and environment that may allow children to acquire more complex regulation strategies to assist in coping with anxiety. Indeed, Rothbart's theory of temperament is constructed on the idea that temperamental characteristics are open to environmental influence, and studies have supported just such a relationship (Colman et al., 2006; Rothbart \& Putnam, 2002). Studies have also supported an interactive process between child temperament and parent behavior (Eisenberg et al., 1999; Kiff, Lengua, \& Zalewski, 2011; Lengua \& Kovacs, 2005). Research on parent-child interactions in anxious families has provided evidence for the active role children play influencing parent-child interactions (Hudson et 
al., 2009; Schrock \& Woodruff-Burden 2010; Williams, Kertz, Schrock, \& WoodruffBorden, 2012). Finally, studies have also shown that child temperament can impact the larger family environment (Crawford, Schrock, \& Woodruff-Borden, 2011). The influence of temperament on child behavior should also be considered. The temperamental qualities of NA and EC have been associated with certain child behaviors such as impulsivity, behavior problems, shyness, social reticence, and avoidance (Eisenberg et al., 1997; Lengua; 2003; Szabó et al., 2008). However, the current study did not directly explore the role of child behavior and future studies should consider the relationship between child temperament and child behavior, and the impact of child behavior on parenting and family functioning.

It is surprising that the relationship between child temperament and negative parenting behavior was not significant as research has consistently documented the relationship between negative parenting and child temperament (Degnan et al., 2008; Feng, Shaw, \& Silk, 2008; Mun, Fitzgerald, Von Eye, Puttler, \& Zucker, 2001). Although the reason for the difference between the current study and previous research is unknown, one possibility is the use of parent self-report measures for parenting behavior. The strength of the relationship between parenting behavior and child anxiety has been shown to fluctuate as a function of reporting method (McLeod et al., 2007) and the same may be true of the relationship between parent behavior and child temperament. Additionally, in an effort to present as more socially acceptable parents may have restricted responding, particularly in relation to negative parenting behaviors such as physical punishment and scolding. Future studies should consider observational methods instead of or in addition to parent seif-report as a potential measure of parent behavior. 
The second hypothesis, that parent anxiety symptoms would predict marital discord, family functioning, and parent behavior, was only partially supported. Lower parent anxiety symptoms did predict less parent negative control behavior. These results are consistent with previous research in the field of child anxiety showing that anxious parents are more likely to exhibit negative or controlling behaviors than non-anxious parents (Barrett, Rapee, Dadds, \& Ryan, 1996; Turner et al., 2003; Wood et al., 2003). It seems plausible that increased parent anxiety would lead to increases in negative parenting behavior. As has been suggested in other research (Schrock \& WoodruffBorden, 2010; Williams et al., 2012), it could be that increased parent anxiety may lead to negative parenting behavior as parents attempt to manage their own anxiety and have few resources left to parent effectively. However, as is outlined by McLeod, Wood, and Weisz (2007), results supporting the relationship between parent anxiety and negative parent behaviors have been inconsistent as results appear to vary as a function of type of measurement and differences in the definition of behaviors. Research should continue to explore the role of parent anxiety in shaping parent behavior and its impact on the development of child anxiety.

The relationship between parent anxiety and parent nurturing behavior was not supported. Previous research has suggested that non-anxious parents are more likely to exhibit positive parenting behaviors such as warmth and autonomy granting (Moore et al., 2004; Whaley et al., 1999). The reasons for this non-significant finding is unknown but again could be the result of the reporting method (parent self-report vs. observational). Another possible explanation could be the fact that there was little variability in the level of parent anxiety symptoms. The mean score on the study anxiety 
measure (BAI) was 5.07, which is considered to reflect mild anxiety symptoms (Beck \& Steer. 1990). As a result, parents in the study likely represent a non-clinical sample. It is probable that increased anxiety symptoms or having a current anxiety diagnosis would strengthen the relationships between parent anxiety and other study variables. Future research should consider the potential differences between anxiety symptoms and anxiety diagnosis, and examine whether specific anxiety symptoms may be related to other study factors such as family environment, parenting, child emotion regulation, or child anxiety.

It is also surprising that the relationships between parent anxiety and marital discord and family functioning were not significant. Research has suggested that parent psychopathology influences the marital relationship often leading to discord, increased conflict, and poor overall family functioning (Dickstein et al., 1998; Frey \& Oppenheimer, 1990; Nomura et al., 2002). However, there is some disagreement regarding the mechanisms behind these relationships and their impact on child anxiety. It has been suggested that parent psychopathology alone may overly simplify the complex interplay of factors underlining marital reiationships and family functioning. Cummings and Davies íCummings, 1994; Cummings \& Davies, 2002; Cummings et al., 2003) have suggested a model in which martial conflict and conflict resolution influence family functioning and child development. Future studies should consider the impact of parent psychopathology on martial conflict and conflict resolution tactics and how conflict and conflict resoiution may influence the development of child emotion regulation skills and child anxiety.

The third hypothesis that family functioning would correlate with marital discord was supported. Again, these results are consistent with current research supporting the 
relationship between marital discord and family functioning (Cowan \& Cowan, 2006). It is likely that higher functioning families are characterized by less marital discord or couples that effectively resolve marital conflict. It is also likely that increased marital discord has a negative impact on family functioning. The potential bi-directional relationship between marital discord and family functioning further underscores the complexity of the factors influencing the family system and future research should continue to explore how these factors might influence each other and child outcomes.

The fourth hypothesis that marital discord and family functioning would predict parenting behavior was only partially supported. Increased family functioning predicted increased parent nurturing behavior. It would make sense that families with higher overall family functioning would exhibit increased supportive parenting behaviors such as nurturance, and research in the field has supported just such a relationship (Belsky, 1984; Tan, Camras, Deng, Zhang, \& Lu, 2012). It could be that higher family functioning provides a more supportive parenting environment characterized by effective co-parent with a broader base of parenting resources.

Given the previous research mentioned above, it is interesting that family functioning was not also related to negative parenting behaviors, and that marital discord was not related to positive or negative parenting behaviors. Although outside the scope of the current study, future research should consider more complex models to examine the family system and how it might impact development of child emotion regulation and child anxiety. For instance, it would be interesting to consider whether the relationship between marital discord andior parent psychopathology and parenting behavior may be mediated by family functioning. 
Overall, the results from the first four hypotheses support the inclusion of parent, child, and family factors in the proposed conceptual model. Although the current study is limited in determining cause and direction of effects, the results from the first four hypotheses highlight the interplay between children and their environment. Future studies should investigate potential transactional relationships connecting these factors.

Next, analyses were conducted to test the relationship between child, parent, and family factors and child emotion regulation and child anxiety. Hypothesis five that child temperament, parent behavior, parent anxiety, family functioning, and marital discord would correlate with child emotion regulation was partially supported. Child emotion regulation was significantly correlated with child NA, child EC, parent anxiety, and family functioning. According to Calkins (1994) emotion regulation is the interaction between biologically based processes and socialization. Indeed, research in the field of child emotion regulation suggests that more complex emotion regulation strategies develop within the context of the caregiving environment (Southam-Gerow \& Kendall, 2002; Thompson, 1994). It is possible that temperament may provide the initial biological underpinnings of child emotion regulation and through the process of socialization and learning more complex regulation strategies are developed.

Child emotion regulation was not significantly related to either marital discord or parenting behavior. Given theoretical work and current research supporting the role of caregivers and socialization in the development of emotion regulation, the lack of a significant relationship is unexpected. However, the lack of a significant direct relationship between marital discord, parenting behaviors, and child emotion regulation does not necessarily exclude these factors as influential in the development of child 
emotion regulation. Future research should consider possible indirect relationships between these factors and child emotion regulation. For instance, as was discuss above, it may be that marital discord or parenting behavior may influence emotion regulation through the family environment.

The sixth hypothesis that child temperament, parent behavior, parent anxiety, family functioning, marital discord, and child emotion regulation would correlate with child anxiety was partially supported. Child anxiety was significantly correlated with parent anxiety, child NA, parent negative control behavior, and child emotion regulation. Parent anxiety has consistently been linked to child anxiety with children of anxious parents being 5 to 7 times more likely to develop anxiety themselves (Beidel $\&$ Turner, 1997). The relationship between parent and child anxiety is likely the result of a genetic vulnerability and environmental risk factors, such as negative or controlling parenting, that combine to shape development. Current conceptual models of child anxiety have hypothesized that child temperament, specifically high NA and low EC, may act as a vulnerability factor for the development of child anxiety (Muris \& Ollendick, 2005). The current study strengthens a growing body of research supporting these conceptual models. The relationship between parenting behavior and child anxiety is well documented but somewhat inconsistent (McLeod et al., 2007). The current study further supports research in the field that parent negativity and control may negatively impact children by undermining children's ability to develop effective skills to help cope with anxiety (Schrock \& Woodruff-Borden, 2010; van der Bruggen et al., 2008). Finally, research has established a connection between child anxiety and emotion regulation (Salters-Pedneault et al., 2006; Suveg et al., 2005). Research in this area has support poor 
emotion regulation in children with anxiety disorders and has suggested that deficits in emotion regulation may be a risk factor in the development of child anxiety. Results from the current study further strengthen this body of research, but also suggest that development of effective emotion regulation may act as a protective factor against the development of child anxiety.

Given that previous research has supported a relationship between child anxiety, child EC (Fox \& Pine, 2012; Lonigan \& Vasey, 2009), parent nurturing behavior (McLeod et al., 2007; Whaley et al., 1999), marital discord (Papp et al., 2004), and family functioning (Hughes et al., 2008; Peleg-Popko \& Dar, 2001) it was unexpected that these relationships were not significant. Again, the lack of a significant direct relationship in the current study between these factors and child anxiety does not necessarily exclude them as influential in the etiology of child anxiety. Future studies should explore possible mediating and moderating variables to help clarify the role of these variables and child anxiety. For instance, as will be discussed in the next section, family functioning was not directly related to child anxiety but was related indirectly thought child emotion regulation. In general, results from hypotheses five and six continue to highlight the complex network of relationships that play a role in the development of child anxiety, and support the inclusion of several study variables in the test of mediation.

Analyses also continue to support the potential interactive relationships between children and their environment. Results connecting temperamental and environmental factors with child emotion regulation provide some evidence to support conceptual 
models placing emotion regulation at the intersection of biological processes and socialization.

Finally, the main hypothesis of the current study, that child emotion regulation would mediate the relationship between child, parent, and family factors and child anxiety, was largely supported. Due to the significant relationships with child emotion regulation and child anxiety, child NA, child EC, parent anxiety, family functioning, and parent negative control behavior were considered as potential mediated variables. In the current study, lower parent anxiety predicted better child emotion regulation, which in turn predicted lower child anxiety. The relationship accounted for $13 \%$ of the variance in child anxiety in the current sample. Similarly, results also support a relationship in which increased child EC predicted better child emotion regulation, which in turn predicted lower child anxiety. The relationship accounted for $9 \%$ of the variance in child anxiety in the current sample. Finally, the mediation analyses supported a relationship in which increased family functioning predicated better child emotion regulation, which in turn predicted lower child anxiety. The relationship accounted for $8 \%$ of the variance in child anxiety in the current sample. Individually, these relationships account for a small percentage of the variance in child anxiety. However, collectively the mediation results account for approximately $30 \%$ of the variance in child anxiety in the current sample. These results are significant given the complexity of the current model and that, in comparison, other studies have estimated that genetic factors also account for apprcximately $30 \%$ of the variance in child anxiety.

Child emotion regulation did not mediate the relationships between parent negative control behavior or child NA and child anxiety. Although contrary to study 
hypotheses, it may be that child NA contributes independently to both child emotion regulation and anxiety. At least one study has identified child NA as a direct contributor to child anxiety (Crawford et al., 2011), and others have implicated temperament in the development of emotion regulation (Bosquet \& Egeland, 2006). Yet another possibility is that child NA and child anxiety could be connected through other mechanisms. For example, studies have identified an association between child NA and the development of certain cognitive biases that have been implicated in the development of child anxiety (Lonigan \& Vasey, 2009; Lonigan, Vasey, Phillips, \& Hazen, 2004). As such, it may be that child NA predisposes children to develop difficulties processing threat related stimuli, which in turn acts as a risk factor for the later development of anxiety. In terms of parenting behavior, the relationships between parent negative control behavior and child anxiety has been well studied, but results have been conflicting and effect sizes typically small. Future research should consider other possible relationships between factors that may better explain this relationship. It may be that negative or controlling parenting behaviors are mediated by the family environment such that ineffective parenting is corrected by the ability of the larger family unit to cope with stress and conflict.

In general, the results from the mediation analysis substantiate earlier results from the current study emphasizing the interchange between child and environmental factors. The mediation results discussed above point to some interesting relationships between child temperament, family environment and child emotion regulation and anxiety. Although the current study is cross-sectional in design, the relationships identified here are potential evidence of a resilience process in which environmental factors could 
promote development of child emotion regulation despite temperamental vulnerability leading to decreased child anxiety. The resilience process would likely be facilitated through a progression of child socialization and learning in which lower parent anxiety, increased family functioning, and parenting behavior help at risk children develop appropriate emotion regulation skills despite temperamental qualities increasing reactivity and decreasing attentional resources. Future studies should explore the impact of family environment on the development of child emotion regulation and child anxiety, particularly in children who exhibit the temperamental combination of high NA and low EC. Future studies should confirm these relationships using a longitudinal design. Consistent with a developmental psychopathology perspective, the results from the analysis of study hypotheses suggest that multifaceted models examining the interaction between individual child differences and environmental influences are necessary to elucidate the developmental trajectory of child anxiety. Although the current results have provided important insights into the relationships between study variables and child anxiety, many questions remain unanswered. For instance, emotion regulation is a complex process and difference aspects of emotion regulation might help better explain some of the mediation results discussed above. Additionally, due to the cross-sectional nature of the current study it is not possible to directly test the impact of emotion regulation on the development of child anxiety, but it is possible to examine differences in emotion regulation based on child anxiety. As such, some additional post-hoc analyses were conducted to help further clarify relationships between some of the study variables. 


\section{Exploratory analyses.}

The BRI of the BRIEF is comprised of three subscales Emotion Control, defined as a child's ability to modulate emotional responses, Inhibit, defined as the ability to not act on impulse, and Shift, defined as the ability to flexibly move between situations and alternate attention.

First, the Emotion Control subscale was explored and was found to be a significant mediator of the relationships between parent anxiety, family functioning, and parent negative control behavior and child anxiety. Parent anxiety, parenting behavior, and family functioning were all significantly related in the current study. It is likely that these factors are involved in a transactional relationship influencing each other and ultimately the way children learn to modulate emotional responses, which in turn impacts child anxiety. Future studies should consider the transactional relationship over time to help identify risk and protective factors in the development of child emotion regulation and anxiety.

Second, the Shift subscale was examined and found to be a significant mediator of the relationships between parent anxiety, family functioning, and child EC. The definition of the Shift subscale is conceptually similar to that of EC, which is defined as the ability to flexibly and adaptively utilize attentional resources to modulate behavior (Rothbart, Rueda, Mayr, Awh, \& Keele, 2005). The relationship between child EC and children's ability to fiexibly move between situations and alternate attention is therefore not surprising, and bolsters research connecting child EC and the development of emotion regulation and child anxiety. 
Finally, the Inhibit subscale was explored and no significant mediation results were found. The lack of significant findings is explained by the fact that the Inhibit subscale was the only one of the three BRI subscales that was not significantly related to child anxiety. These results suggest that impulsivity is not a significant factor in the development of emotion regulation and child anxiety. Child temperament and development of emotion regulation skills have both been linked to the development of child anxiety and externalizing disorders. One of the shortcomings of research in this area is the lack of specificity in relating factors to specific child outcomes. Impulsivity could be a factor that helps differentiate between developmental trajectories.

Results from the post-hoc analysis of the BRI mediator variable support a series of complex relationships between child temperament, family environment, parent behavior, parent anxiety, and child emotion regulation and child anxiety. The relationships between parent anxiety, family functioning, and parent negative control behavior and the Emotion Control subscale further support Calkins (2007) research in which parenting and the family environment are the primary socialization agent for the development of child emotion regulation skills. The associations between parent anxiety, family functioning, child EC and the Shift subscale provide further evidence that temperamental qualities are open to environmental influence as suggested by Rothbart (2000), and that there is likely a connection between environmental influence of temperament and the socialization that is thought to help children develop more complex emotion regulation strategies. it is conceptually interesting that the child temperament factors were not related to the Emotion Control subscale but only related to the Shift subscale. One way to potentially connect current results and the research by Rothbart and 
Calkins is to consider the impact of child development. Work by Derryberry and Rothbart (1997) has linked the temperamental quality of EC to development of specific neural structures in the brain, and research by Kopp (1982) has proposed these neural structures do not fully develop until children are 3-6 years old. It could be that environmental influences help shape the temperamental quality of EC while neural pathways are still developing and younger children are developmentally less able to self-regulate and probably more dependent on their caregivers for assistance. However, it is possible that as children get older and neural pathways become more developed, they act as the foundation for high order emotion regulation strategies, which are acquired through sociaiization and learning. Although the current study is limited by the cross-sectional design and child age range, future studies should explore these relationships longitudinally to help clarify the relationship between temperament and emotion regulation and the development of child anxiety. Empirical support for the transition between child temperamental characteristics and successful development of child emotion regulation promoted by the family environment would provide compelling evidence of a resilience process in children temperamental vulnerable to the development of anxiety, and the current study has established the initial framework to further explore these relationships.

The primary purpose of the current study was to propose a conceptual model of resilience in children at risk for developing anxiety, and take the first step in validating the model by testing emotion regulation as a mediator in the relationship between child, parent, and family factors and child anxiety. The next step would be to test how child, parent, and family variables influence child emotion regulation and how child emotion 
regulation in iurn influences child anxiety. Due to the cross-sectional design of the study, it is not possible to directly test these relationships. In an effort to further explore these relationships, additional post-hoc analyses were conducted to examine the impact of parent anxiety, child temperament, parent behavior, and family functioning on child emotion regulation in high and low anxious children. Results from the analyses indicated that parent anxiety and child NA were important in the development of child emotion regulation in both high and low anxious children. Closer inspection of the regression beta weights revealed little difference between high and low anxious children in the relationship between parent anxiety and child emotion regulation. However, regression beta weights did indicate a potentially greater influence of child NA on child emotion regulation in high anxious versus low anxious children. Results also showed that family functioning had a greater impact on child emotion regulation in high anxious children. Neither child EC nor parent negative control behavior was a significant predictor of child emotion regulation. The results described here suggest that child temperamental traits and family environment may have a more significant impact on child emotion regulation in children with higher levels of anxiety. A focus on development of emotion regulation through skills training could be an important prevention strategy in child with temperamental vuinerabilities or a valuable treatment intervention for children who are already experiencing increased anxiety symptoms.

\section{Implications for the conceptual model}

Results from the current study inform the proposed conceptual model in several ways. The current study has supported a complex model in which child temperament, family functioning, parent anxiety, parenting behavior, and marital ảiscord are 
interrelated, and future studies should examine poiential transactional relationships between these factors. Results from the current study also supported relationships between child temperament, parent anxiety, and family functioning and child emotion regulation, as well as, relationships between child temperament, parent behavior, parent anxiety, and child anxiety. Finally, emotion regulation as a mediator of the relationship between parent anxiety, family functioning, child EC and child anxiety was confirmed. However, not all hypothesized relationships were supported: Additionally, exploratory analyses point to potential distinct aspects of emotion regulation (e.g., emotion control vs. shift) and differences in mediated factors based on which aspect of emotion regulation is examined. Future studies should further examine aspects of emotion regulation and adjust the current model to accommodate those findings. See figure 5 for a graphical repiesentation of supported relationships from the current study. 
Figure 5.Graphical summary of hypothesis testing.

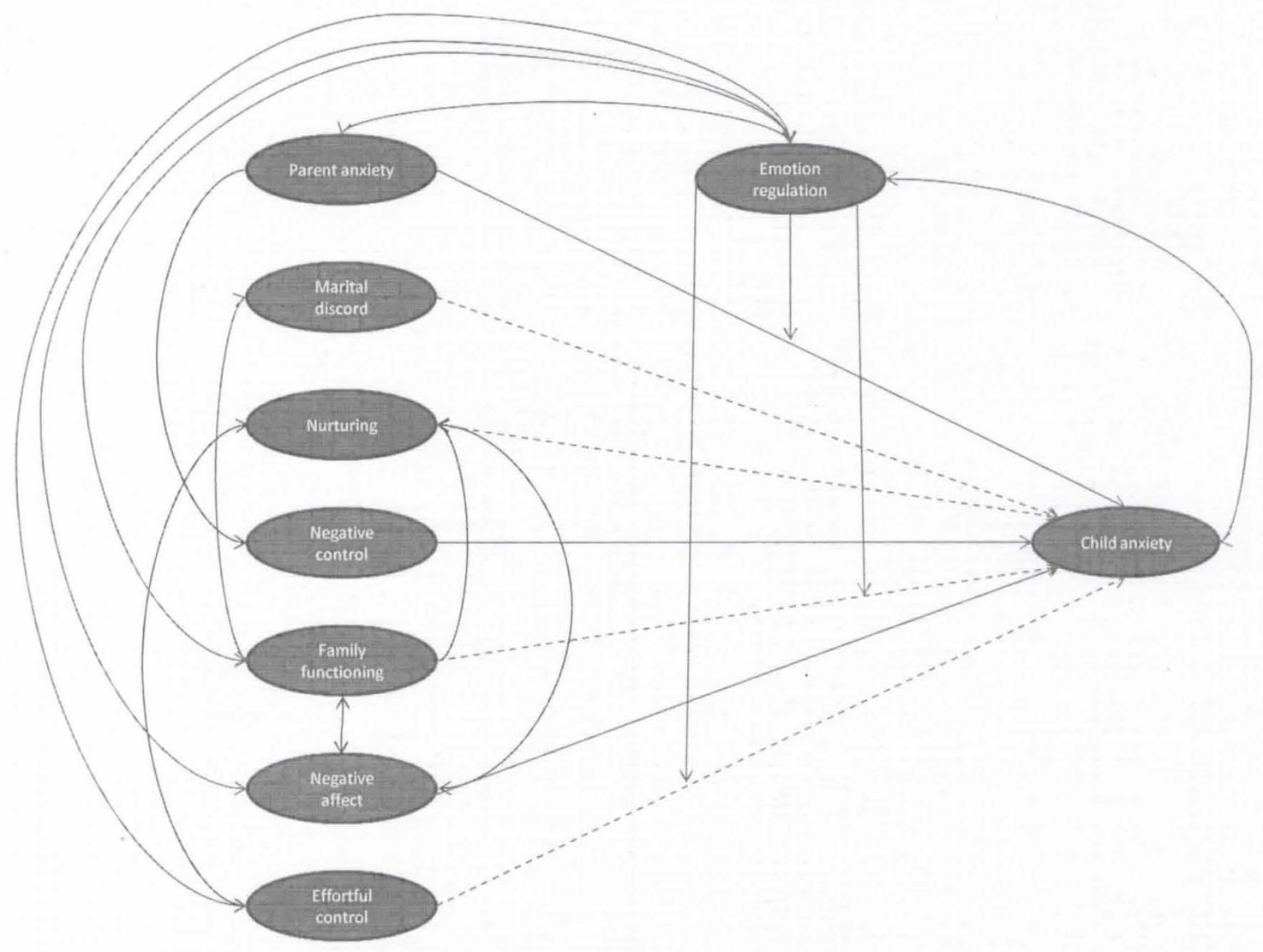

Note: Solid lines indicate significant relationships.

\section{Limitations of the current study}

The purpose of the current study was to take the first step in testing a model of resilience in children at risk for developing anxiety. Results from the study suggest that emotion regulation plays an important role in the relationship between intrinsic and extrinsic child factors and the development of anxiety in children. Although the study has many strengths, there are several important limitations.

The first limitation is the cross-sectional study design. Although appropriate for establishing child emotion regulation as mediator in the development of child anxiety, the cross-sectional design does prevent the exploration of dynamic, transactional 
relationships between study variables, and preciludes the examination of which combinations of factors may help facilitate the process of resilience at different stages of development. Also, the cross-sectional nature prevents any conclusions related to direction or cause in the relationships between study variables. Consistent with a developmental psychopathology perspective, the influence of child development should be considered, particularly in regard to the temperamental attribute of EC and the impact of parenting.

The second limitation is the narrow child age range. Although the narrow age range was helpful in the current study as differences in child EC could be attributed to individual differences in the temperamental trait and not maturational differences, it also prevented the examination of differences between child EC and development of more complex emotion regulation due to child socialization

The third limitation is the nature of the study sample. The sample was not randomly selected, was predominately European American, and was unevenly drawn from three relatively different geographic areas. As such, generalizability to the larger population and interpretation of results should be done with caution.

The fourth limitation is the range of parent and child anxiety scores on the BAI and BAI-Y. The average child anxiety score was 12.12 and the average adult score was 5.07 both falling in the mild or average range on the Beck measures (Beck \& Steer, 1990; Beck et al., 2001). The scores are consistent with a community sample, but future studies may want to consider examining differences in the proposed model between clinical and non-clinical samples. 
Finally, the study participants were primarily mothers and their children with only a few fathers participating in the study. Although this is consistent with most studies within the field of child anxiety, it is a known shortcoming and future studies should consider the role of fathers possibly exploring triadic versus dyadic interactions.

\section{Summary and future directions}

In conclusion, the current study has summarized empirical and theoretical work from several research literatures and proposed a conceptual model of resilience in children at risk for the development of anxiety. As a first step in testing this model, the current study examined the role of child emotion regulation as a mediator between child, parent, and family factors and child anxiety. Results from the current study support a complex model in which child temperament, family functioning, and parenting behavior, and parent anxiety are interrelated and influence child emotion regulation, which in turn impacts child anxiety.

The temperamental attributes of negative reactivity and effortful control appear to be associated with the development of anxiety, but not exclusively as research has also implicated these temperamentai qualities in children with externalizing disorders. Results from the current study further support the role of child NA and EC in child anxiety and suggest impulsivity as possible factor to help explain the relationship between child temperament and internalizing and externalizing disorders. High NA and low EC have also been implicated in the development of attentional biases and anxiety. The relationship between child NA and child anxiety was not mediated by child emotion contro! in the current study suggesting a direct link between NA and child emotion regulation and anxiety, or the possibility of alternate pathway possibly through attentional 
biases. Problems with emotion regulation have been implicated in the development of psychopathology, but few studies have looked at anxiety specifically. The current study supported a relationship between emotion regulation and child anxiety and exploratory analyses suggest that emotion regulation may be more important in children with higher levels of anxiety. Rothbart (2006) has suggested the temperament is open to environmental influence, and work by Calkins (1994) has supported the integral role of parents in the development of successful emotion regulation skills in children. In the current study, parent and family factors were related to a specific emotion control factor of the BRIEF and child temperament (EC) was related to a specific attention factor of the BRIEF. It may be that temperament lays the early groundwork for later development of more complex emotion regulation strategies, which are assimilated from the social environment. Parents may play a more significant role assisting children with temperamental attributes that undermined the normal development of emotion regulation. Future research should explore children with the temperamental combination of high NA and low effortful control, which have been identified as a vulnerability factor in the development of child anxiety. The confluence of environmental factors such as family environment and parenting influencing the development of emotion regulation and changing the deveiopmental trajectory in temperamental vulnerable children is evidence of a resilience process. Identification of a resilience process would have important implications for prevention and treatment. For instance, early identification of children with high NA and low EC could lead to individual interventions aimed an attention training and psychoeducation of emotion, as well as, family level interventions aimed at skills training of effective emotion reguilation strategies. 
The model and results presented here provide an excellent starting point from which to consider these issues, but considerable work remains to be done. Many of the relationships suggested in the model were based on theoretical work and/or research outside the field of child anxiety and further testing should be completed to confirm the results. Clarifying a model of resilience in children at risk for the development of anxiety is vitally important. Not only would such a model provide valuable information on the developmental course of anxiety disorders, but would also undoubtedly lead to important advances in the prevention and treatment of anxiety in children. The next step is systematic testing of the hypothesized model while considering the impact of cognitive development and the potential differing role of parents and peers with child age. Furthermore, identification of vulnerability, risk, and protective factors is only the first step in understanding resilience. Resilience, by definition, is a process which unfolds across time and is not a static outcome. Research should also be directed at identifying the underlying processes that allow children to adapt and more successfully manage adversity. 


\section{REFERENCES}

Ahadi, S. A., \& Rothbart, M. K. (1994). Temperament, development, and the Big Five. In C. F. Halverson, Jr., G. A. Kohnstamm \& R. P. Martin (Eds.), The developing structure of temperament and personality from infancy to adulthood. (pp. 189207). Hillsdale, NJ England: Lawrence Erlbaum Associates, Inc.

Anthony, J. L., Lonigan, C. J., Hooe, E. S., \& Phillips, B. M. (2002). An affect-based, hierarchical model of temperament and its relations with internalizing symptomatology. Journal of Clinical Child and Adolescent Psychology, 31(4), 480-490.

Baker, R., Holloway, J., Thomas, P. W., Thomas, S., \& Owens, M. (2004). Emotional processing and panic. Behaviour Research and Therapy, 42(11), 1271-1287. doi: 10.1016/j.brat.2003.09.002

Baron, R. M., \& Kenny, D. A. (1986). The moderator - mediator variable distinction in social psychological research: Conceptual, strategic, and statistical considerations. Journal of Personality and Social Psychology, 51(6), 1173-1182.

Barrett, P. M., Rapee, R. M., Dadds, M. M., \& Ryan, S. M. (1996). Family enhancement of cognitive style in anxious and aggressive children. $J$ Abnorm Child Psychol, 24(2), 187-203.

Bates, J. E. (1987). Temperament in infancy. In J. D. Osofsky (Ed.), Handbook of infant development (2nd ed.). (pp. 1101-1149). Oxford England: John Wiley \& Sons.

Beck, A. T., Epstein, N., Brown, G., \& Steer, R. A. (1988). An inventory for measuring clinical anxiety: Psychometric properties. [Print]. Journal of Consulting and Clinical Psychology, 56(6), 893-897.

Beck, A. T., \& Steer, R. A. (1990). Beck Anxiety Inventory Manual. San Antonio, TX: Psychological Corporation.

Beck, J. S., Beck, A. T., \& Joliy, J. (2001). Manual for the Beck Youth Inventories of Emotional and Social Impairment. San Antonio, TX: The Psychological Corporation.

Beidel, D. C., \& Turner, S. M. (1997). At risk for anxiety: I. Psychopathology in the offspring of anxious parents. Journal of the American Academy of Child \& Adolescent Psychiatry, 36(7), 918-924.

Belsky, J. (1984). The determinants of parenting: A process model. Child Development, 55(1), 83-96. doi: $10.2307 / 1129836$ 
Beisky, J., Fisn, M., \& Isabella, R. A. (1991) Continuity and discontinuity in infant negative and positive emotionality: Family antecedents and attachment consequences. Developmental Psychology, 27(3), 421-431.

Biederman, J., Petty, C., Faraone, S. V., Henin, A., Hirshfeld-Becker, D., Pollack, M. H., Rosenbaum, J. F. (2006). Effects of parental anxiety disorders in children at high risk for panic disorder: A controlled study. Journal of Affective Disorders, 94(13), 191-197.

Biederman, J., Petty, C., Faraone, S. V., Hirshfeld-Becker, D. R., Henin, A., Dougherty, M., Rosenbaum, J. F. (2005). Parental predictors of pediatric panic disorder/agoraphobia: A controlled study in high-risk offspring. Depression and Anxiety. 22(3), 114-120.

Biederman, J., Petty, C., Hirashfeld-Becker, D. R., Henin, A., Faraone, S. V., Dang, D., Rosenbaum, J. F. (2006). A controlled longitudinal 5-year follow-up study of children at high and low risk for panic disorder and major depression. Psychological Medicine, 36(8), 1141-1152.

Bittner, A., Egger, H. L., Erkanli, A., Costello, E. J., Foley, D. L., \& Angold, A. (2007). What do childhood anxiety disorders predict? Journal of Child Psychology and Psychiatry, 48(12), 1174-1183.

Bogeis, S. M., \& Brechman-Toussaint, M. L. (2006). Family issues in child anxiety: attachment, family functioning, parental rearing and beliefs. Clin Psychol Rev, $26(7), 834-856$.

Bögels, S. M., \& Brechman-Toussaint, M. L. (2006). Family issues in child anxiety: Attachment, family functioning, parental rearing and beiiefs. Clinical Psychology Review, 26(7), 834-856. doi: 10.1015/j.cpr.2005.08.001

Bosquet, M., \& Egeland, B. (2006). The development and maintenance of anxiety symptoms from infancy through adolescence in a longitudinal sample.

Development and Psychopathology, 18(2), 517-550. doi: 10.1017 is0954579406060275

Buss, A. H., \& Plomin, R. (1975). A temperament theory of personaitity development. Oxford England: Wiley-Interscience.

Calkins, S. D. (1994). Origins and outcomes of individual differences in emotion regulation. Monograpins of the Society for Research in Child Deveiopment, $59(2$. 3), 53-72, 250-283. doi: 10.2307/1166138

Calkins, S. D., \& Fox, N. A. (200i2) Self-regulatory processes in early personality development: A muitilevel approach to the stidy of childhood social withdrawal and aggression. Development and $P_{s y}$ chopathoiogy, 14(3), 477-498. doi: $10.1017 / \mathrm{s} 0954579402001305 \mathrm{x}$

Calkins, S. D. \& Hill, A. (2097). Caregiver Influences on Emerging Emotion Regulation: Biological anç Environmentál Transactions in Early Development. In j. J. Gross (Ed.), Kandbook of emoion regulation. (pp. 229-248). New York, NY US: Guifford Press. 
Calkins, S. D., \& Johnson, M. C. (1998). Toddler regulation of distress to frustrating events: Temperamental and maternal correlates. Infant Behovior \& Development, 2l(3), 379-395. doi: 10.10;6/s0163-6383(98)90015-7

Calkins, S. D., Smith, C. L., Gill, K. L., \& Johnson, M. C. (1998). Maternal interactive style across contexts: Reiations to emotional, behavioral, and physiological regulation during toddlerhood. Social Development, 7(3), 350-369. doi: 10.1111/1467-9507.00072

Caspi, A., Harrington, H., Milne, B., Amell, J. W., Theodore, R. F., \& Moffitt, T. E. (2003). Children's Behavioral Styles at Age 3 Are Linked to Their Adult Personality Traits at Age 26. Journal of Personality, 71(4), 495-513.

Caspi, A., \& Silva, P. A. (1995). Temperamental qualities at age three predict personality traits in young adulthood: Longitudinal evidence from a birth cohort. Child Development, 66(2), 486-498.

Chapman, L. K., \& Woodruff-Borden, J. (2009). The impact of family functioning on anxiety symptoms in African American and European American young adults. Personality and Individual Differences, 47(6), 583-589. doi: 10.1016/j.paid.2009.05.012

Cicchetti, D., Ackerman, B. P., \& Izard, C. E. (1995). Emotions and emotion regulation in developmental psychopathology. Development and Psychopathology, 7(1), 110. doi: $10.1017 / \mathrm{s} 0954579400006301$

Cicchetti, D., \& Toth, S. L. (1997). Transactional ecological systems in developmental psychopathology. In S. S. Luthar, J. A. Burack, D. Cicchetti \& J. R. Weisz (Eds.), Developmental psychopathology: Perspectives on adjustment, risk, and disorder. (pp. 317-349) New York, NY US: Cambridge University Press.

Cisler, J. M., Olatunji, B. O., Feldner, M. T., \& Forsyth, J. P. (2010). Emotion regulation and the anxiety disorders: An integrative review. Journal of Psychopathology and Behavioral Assessment 32(1), 68-82. doi: 10.1007/s10862-009-9161-1

Clark, L. A., Kochanska, G., \& Ready, R. (2000). Mothers' personality and its interaction with child temperament as predictors of parenting behavior. Journal of Personality and Social ${ }^{D}$ sychology, 79(2), 274-285.

Colman, R. A., Hardy, S. A., Albert, M., Raffaelli, M., \& Crockett, L. (2006). Early Predictors of Self-Reguiation in Middle Childhood. Infant and Child Development, 15(4), 421-437.

Costello, E. I., Egger, H. L., \& Argold, A. (2004). Developmental Epidemiology of Anxiety Disorders. In T. H. Oilendick \& J. S. March (Eds.), Phobic and anxiety disorciers in children and adolescents: A clinician's guide to effective psychosocial and pharmacological interventions. (pp. 61-91). New York, NY US: Oxford University Press.

Costello, E. J. Mustillo, S., Erkanli, A., Keeler, G , \& Angold, A. (2003). Prevalence and Development of Psychiatric Disorders in Childhood and Adolescence. Archives of Generai Psychiatry, 60(8), 837-844. doi: 10.1001/archpsyc.60.8.837 
Cowan, P. A., \& Ccwan, C. P. (2006). Developmental psychopathology from family systems and family risk factors perspectives Implications for family research, practice, and policy. In D. Cicchetti \& D. J. Conen (Eds.), Developmental psychopathology Vol 1: Theory and method (2nd ed.). (pp. 530-587). Hoboken, NJ US: John Wiley \& Sons Inc.

Crawford, N. A., Schrock, M., \& Woodruff-Borden, J. (2011). Child internalizing symptoms: Contributions of child temperament, maternal negative affect, and family functioning. Child Psychiatry and Human Development, 42(1), 53-64. doi: $10.1007 / \mathrm{s} 10578-010-0202-5$

Cross, D. G., \& Sharpley, C. F. (1981). The Locke-Wallace Marital Adjustment Test reconsidered: Some psychometric findings as regards its reliability and factorial validity. Educational and Psychological Measurement, 4I(4), 1303-1306.

Cummings, E. M. (1994). Marital conflict and children's functioning. Social Development, 3(1), 16-36. doi: 10.1111/j.1467-9507.1994.tb00021.x

Cummings, E. M., \& Davies, P. T. (2002). Effects of marital conflict on children: Recent advances and emerging themes in process-oriented research. Journal of Child Psychology and Psychiatry, 43(1), 31-63. doi: 10.1111/1469-7610.00003

Cummings, E. M., Davies, P. T., \& Campbell: S. B. (2000a). Complex Patterns of Influence: Risk and Proteciive Factors Developmental psychopathology and family process: Theory, research, and clinical implications. (pp. 35-55). New York, NY US: Guilford Press.

Cummings, E. M., Davies, P. T., \& Campbell, S. B. (2000b). Developmental psychopathology and family process: Theory, research, and clinical implications. New York, NY US: Guilford Press.

Cumnings, E. M., Goeke-Morey, M. C., \& Papp, L. M. (2003). Children's responses to everyday marital connlict tactics in the home. Child Development, 74(6), 19181929. doi: $10.1046 / \mathrm{j} .1467-8624.2003 .00646 . \mathrm{x}$

Dadds, M. R., \& Powell, M. B. (1991). The relationship of interparental conflict and global marital adjustment to aggression, anxiety, and immaturity in aggressive and nonclinic children. Journal of Abnormal Child Psychology: An official publication of the International Society for Research in Child and Adolescent Psychopathology, 19(5), 553-567. doi: 10.1007/bf00925820

Dadds, M. R.. \& Roth, J. H. (2001). Family processes in the development of anxiety problems. In M. W. Vasey \& M. R. Dadds (Eds.), (pp. 278-303): Oxford University Press.

Degnan, K. A., Almas, A. N., \& Fox, N. A. (2010).. Temperament and the environment in the etiology of childhood anxiety. Journai of Child Psychology and Psychiatry, 51(4), 497-517. doi: 10.1111/j.1469-7610.2010.02228.x

Degnan, K. A., \& Fox, N. A. (2007). Behavioral inhibition and anxiety disorders: Multiple levels of a resilience process. Development and Psychopathology, 19(3), 729-746. 
Degnan, K. A., Henderson, H A., Fox, N. A., \& Rubin, K. H. (2008). Predicting social wariness in middle childhood: The moderating roles of childcare history, maternal personality and maternal behavior. Social Development, 17(3), 471-487. doi: 10.1111/j.1467-9507.2007.00437.x

Derryberry, D., \& Rothbart, M. K. (1997). Reactive and effortful processes in the organization of temperament. Development and Psychopathology, 9(4), 633-652.

Dickstein, S., Seifer, R., Hayden, L. C., Schiller, M., Sameroff, A. J., Keitner, G., . . . Magee, K. D. (1998). Levels of family assessment: II. Impact of maternal psychopathology on family functioning. Journal of Family Psychology, 12(1), 2340.

Dumas, J. E., LaFreniere, P. J., \& Serketich, W. J. (1995). 'Balance of power': A transactional analysis of control in mother-child dyads involving socially competent, aggressive, and anxious children. [Print]. Journal of Abnormal Psychology, 104(1), 104-113.

Durbin, C. E., Hayden, E. P., Klein, D. N., \& Olino, T. M. (2007). Stability of laboratoryassessed temperamental emotionality traits from ages 3 to 7. Emotion, 7(2), 388399.

Eisenberg, N., Cumberland, A., \& Spinrad, T. L. (1998). Parental socialization of emotion. Psychological Inquiry, 9(4), 241-273. doi: 10.1207/s15327965pli0904_1

Eisenberg, N., \& Fabes, R. A. (1992). Emotion, regulation, and the development of social competence. In M. S. Clark (Ed.), Emotion and social behavior. (pp. 119-150). Thousand Oaks, CA US: Sage Publications, Inc.

Eisenberg, N., Fabes, R. A., Bernzweig, J., \& Karbon, M. (1993). The relations of emotionality and regulation to preschoolers' social skills and sociometric status. Child Development, 64(5), 1418-1438.

Eisenberg, N., Fabes, R. A., Murphy. B., \& Maszk, P. (1995). The role of emotionality and regulation in children's social functioning: A longitudinal study. Child Development, 66(5), 1360-1384.

Eisenberg, N., Fabes, R. A., Shepard, S. A., Guthrie, I. K., Murphy, B. C., \& Reiser, M. (1999). Parental reactions to children's negative emotions: Longitudinal relations to quality of children's social functioning. Child Development, 70(2), 513-534. doi: $10.1111 / 1467-8624.00037$

Eisenberg, N., Guthrie, I. K., Fabes, R. A., Reiser, M., Murphy, B. C., Holgren, R., . . . Losoya, S. (1997). The relations of regulation and emotionality to resiliency and competent social functioning in elementary school children. Child Development, 68(2), 295-311.

Eisenberg, N., Hofer, C., \& Vaughan, J. (2007). Effortful Control and Its Socioemotional Consequences. In J. J. Gross (Ed.), Handbook of emotion regulation. (pp. 287306). New York, NY US: Guilford Press.

Eley, T. C. (2001). Contributions of behavioral genetics research: Quantifying genetic, shared environmental and nonshared environmental influences. In M. W. Vasey 
\&. M. R. Dadds (Eds.), The developmentai psychopathology of anxiety. (pp. 4559). New York, NY. US: Oxford University Press.

Epstein, N. B., Baldwin, L. M., \& Bishop, D. S. (1983). The McMaster Family Assessment Device. [Print]. Journal of Marital \& Family Therapy, 9(2), 171-180.

Faul, F., Erdfelder, E., Lang, A. G., \& Bauchner, A. (2007). G*Power 3: A felxible statistical power analysis program for the social, behavioral, and biomedical sciences. Research Methods, 39, 175-191.

Feng, X., Shaw, D. S., Kovacs, M., Lane, T., O'Rourke, F. E., \& Alarcon, J. H. (2008). Emotion regulation in preschoolers: The roles of behavioral inhibition, maternal affective behavior, and maternal depression. Journal of Child Psychology and Psychiatry, 49(2), 132-141.

Feng, X., Shaw, D. S., \& Silk, J. S. (2008). Developmental trajectories of anxiety symptoms among boys across early and middle childhood. Journal of Abnormal Psychology, 117(1), 32-47. doi: 10.1037/0021-843x.117.1.32

Field, A. (2005). Discovering Statistics Using SPSS (2nd ed. ed.). London: Sage Publications.

Field, T. (1994). The effects of mother's physical and emotional unavailability on emotion regulation. Monographs of the Society for Research in Child Development, 59(2-3), 208-227, 250-283. doi: 10.2307/1166147

Fincham, F. D., Grych, J. H., \& Osborne, L. N. (1994). Does marital conflict cause child maladjustment? Directions and challenges for longitudinal research. Journal of Family Psychology, 8(2), 128-140. doi: 10.1037/0893-3200.8.2.128

Fox, N. A., Henderson, H. A., Marshall, P. J., Nichols, K. E., \& Ghera, M. M. (2005). Behavioral Inhibition: Linking Biology and Behavior within a Developmental Framework. Annual Review of Psychology; 56, 235-262.

Fox, N. A., \& Pine, D. S. (2012). Temperament and the emergence of anxiety disorders. Journal of the American Academy of Child \& Adolescent Psychiatry, 51(2), 125128. doi: 10.1016/j.jaac.2011.10.006

Frey, J., \& Oppenheimer, K. (1990). Family dynamics and anxiety disorders: A clinical investigation. Family Systems Medicine, 8(1), 28-37.

Fristad, M. A., \& Clayton, T. L. (1991). Family dysfunction and family psychopathology in child psychiatry outpatients. Journal of Family Psychology, 5(1), 46-59. doi: 10.1037/0893-3200.5.1.46

Fritz, M. S., \& MacKinnon, D. P. (2007). Required sample size to detect the mediated effect. Psychological Science, 18(3), 233-239. doi: 10.1111/j.14679280.2007.01882 x

Gar, N. S., \& Hudson, I. L. (20018). An examination of the interactions between mothers and children with anxiety disorders. Behaviour Research and Therapy, 46(12), 1266-1274. doi: 10.1016/j.brat.2008.08.006 
Garber, J, \& Dodge, K. A. (1991). The development of Emotion regulation and dysreguiation. New York, NY US: Cambridge Liniversity Press.

Garmezy, N. (1974). Children at risk: The search for the antecedents of schizophrenia: II. Ongoing research programs, issues, and intervention. Schizophrenia Bulletin, $1(9), 55-125$.

Garmezy, N., \& Streitman, S. (1974). Children at risk: The search for the antecedents of schizophrenia: I. Conceptual models and research methods. Schizophrenia Bulletin, 1(8), 14-90.

Gilliom, M.. \& Shaw, D. S (2004). Codevelopment of externalizing and internalizing problems in early childhood. Development and Psychopathology, 16(2), 313-333.

Ginsburg, G. S., Siqueland, L., Masia-Warner, C., \& Hedtke, K. A. (2004). Anxiety disorders in children: Family matters. Cognitive and Behavioral Practice, 11(1), 28-43. doi: 10.1016/s1077-7229(04)80005-1

Gioia, G. A., Isquith, P. K., Guy, S. C., \& Kenworthy, L. (2000). Behavior Rating Inventory for Executive Function: Prefessional Manual. Odessa: Psychological Assessment Resources, Inc.

Goeke-Morey, M. C., Cummings, E. M., \& Papp, L. M. (2007). Children and marital conflict resolution: Implications for emotional security and adjustment. Journal of Family Psychology, 21(4), 744-753. doi: 10.1037/0893-3200.21.4.744

Gregory, A. M., \& Eley, T. C. (2007). Genetic influences on anxiety in children: What we've learned and where we're heading. Clinical Child and Family Psychology Review, 10(3), 199-212.

Grills-Taquechel, A., \& Ollendick, T. H. (2007). Introduction to special issue:

Developments in the etiology and psychosocial treatments of anxiety disorders in children and adolescents. Clinical Child and Family Psychology Review, 10(3), i97-198. doi: 10.1007/s10567-007-0026-4

Hayes, A. F. (2009). Beyond Baron and Kenny. Statistical mediation analysis in the new millennium. Communication Monographs, 76(4), 408-420. doi: $10.1080 / 03637750903310360$

Hayes, A. F. (in review-a). An Analytical Primer and Computational Tool for Observed Variable Mediation, Moderation, and Conditional Process Modeling.

Hayes, A. F. (in review-b). Indirect and Direct Effects of a Multicategorical Causal Agent in Statistical Mediation Analysis. Manuscript submitted for publication.

Hettema, J. M., Neale, M. C., \& Kendler, K. S. (2001). A review and meta-analysis of the genetic epidemiology of anxiety disorders. The American Journal of Psychiatry, $158(10), 1568-1578$.

Hettema, J. M., Prescott, C. A.. Myers, J. M., Neale, M. C., \& Kendler, K. S. (2005). The Structure of Genetic and Environmental Risk Factors for Anxiety Disorders in Men and Women. Archives of General Psychiatry, o2(2), 182-189. 
Hewitt, P. L., \& Norton, G R. (i993). The Beck Anxiety Inventory: A psychometric analysis. [Print]. Psychological Assessment. 5(4), 408-412.

Hudison, J. L., Doyle, A. M., \& Gar, N. (2009). Child and maternal influence on parenting behavior in clinically anxious children. Journal of Clinical Child and Adolescent Psychology, 38(2), 256-262. doi: 10.1080/15374410802698438

Hudson, J. L., \& Rapee, R. M. (2001). Parent--child interactions and anxiety disorders: An observational study. Behaviour Research and Therapy, 39(12), 1411-1427.

Hughes, A. A., Hedtke, K. A., \& Kendall, P. C. (2008). Family functioning in families of children with anxiety disorders. Journal of Family Psychology, 22(2), 325-328. doi: $10.1037 / 0893-3200.22 .2 .325$

Jakes, S. S., \& DeBord, K..(2010). The interface of family, school, and community factors for the positive development of children and youth. Journal of Prevention \& Intervention in the Community, 38(3), 177-182. doi: $10.1080 / 10852352.2010 .486293$

Jekielek, S. M. (1998). Parental conflict, marital disruption and children's emotional wellbeing. Social Forces, 76(3), 905-936.

Kiff, C. J., Lengua, L. J., \& Zalewski, M. (2011). Nature and nurturing: Parenting in the context of child temperament. Clinical Child and Family Psychology Review. 14(3), 251-301. doi: 10.1007/s10567-011-0093-4

Kochanska, G. (1993). Toward a synthesis of parental socialization and child temperament in early development of conscience. Child Development, 64(2), 325347 .

Kochanska, G. (1995). Children's temperament, mother's discipline, and security of attachment: Multiple pathways to emerging internalization. Child Development, 66(3), 597-615. doi: 10.2307/1131937

Kochanska, G., \& Murray, K. T. (2000). Mother-child mutually responsive orientation and conscience development: From toddler to early schooi age. Child Development, 71(2), 417-431. doi: 10.1111/1467-8624.00154

Kochanska, G., Murray, K. T., \& Harlan, E. T. (2000). Effortful control in early childhood: Continuity and change, antecedents, and implications for social development. Developmental Psychology, 36(2), 220-232. doi: 10.1037/00121649.36.2.220

Komsi, N., Räikkönen, K., Heinonen, K., Keskivaara, P., Strandberg, T. E., Järvenpää, A.-L., \& Pesonen, A.-K. (2008). Transactional development of parent personality and child temperament. European Journal of Personality, 22(6), 553-573. doi: 10.1002/per.690

Kopp, C. B. (1982). Antecedents of self-regulation: A developmental perspective. Developmental Psychology, 18(2), 199-214. doi: 10.1037/0012-1649.18.2.199

Lengua, L. I. (2002). The contribution of emotionality and self-regulation to the understanding of children's response to multiple risk. Child Development, 73(1), 144-161. 
Lergua, L. J. (2003). Associations ämong emotionality. self-regulation, adjustment problems, and positive adjustment in middle childhood. Journal of Applied Developmental Psychology, 24(5), 595-618.

Lengua, L. J., \& Kovacs, E. A. (2005). Bidirectional associations between temperament and parenting and the prediction of adjustment problems in middle childhood. Journal of Applied Developmental Psychology 26(1), 21-38.

Locke, H. J., \& Wallace, K. M. (1959). Short marital-adjustment and prediction tests: Their reliability and validity. Marriage \& Family Living, 21, 251-255. doi: $10.2307 / 348022$

Lonigan, C. J., \& Phillips, B. M. (2001). Temperamental influences on the development of anxiety disorders. In M. W. Vasey \& M. R. Dadds (Eds.), The developmental psychopathology of anxiety. (pp. 60-91). New York, NY US: Oxford University Press.

Lonigan, C..J., \& Vasey, M. W. (2009). Negative affectivity, effortful control, and attention to threat-relevant stimuli. Iournal of Abnormal Child Psychology: An official publication of the International Society for Research in Child and Adolescent Psychopathology, 37(3), 387-399.

Lonigan, C. J., Vasey, M. W., Phillips, B. M., \& Hazen, R. A. (2004). Temperament, Anxiety, and the Processing of Threat-Relevant Stimuli. Journal of Clinical Child and Adolescent Psychology, 33(1), 8-20.

Luthar, S. S. (1991). Vulnerability and resilience: A study of high-risk adolescents. Child Development, 62(3), 600-616. doi: 10.2307/1131134

Luthar, S. S. (2006). Resilience in development: A synthesis of research across five decades. In D. Cicchetti \& D. J. Cohen (Eds.), Developmental psychopathology, Vol 3: Risk, disorder, and adaptation (2nd ed.). (pp. 739-795). Hoboken, NJ US: John Wiley \& Sons Inc.

Luthar, S. S., Cicchetti, D., \& Becker, B. (2000). The construct of resilience: A critical evaluation and guidelines for future work. Child Development, $71(3), 543-562$. doi: $10.1111 / 1467-8624.00164$

Malcarne, V. L., Hansdottir; 1., \& Merz, E. L. (2001). Vulnerability to anxiety disorders in childhood and adolescence. In R. E. Ingram \& J. M. Price (Eds.), Vulnerability to psychopathology: Risk across the lifespan. (pp. 271-303). New York, NY US: Guilford Press.

Masten, A. S., Best, K. M., \& Garmezy, N. (1990). Resilience and development: Contributions from the study of children who overcome adversity. Development and Psychopathology, 2(4), 425-444.

McLeod, B. D., Wood, J. J., \& Weisz, J. R. (2007). Examining the association between parenting and childhood anxiety: A meta-analysis. Clinical Psychology Review, $27(2), 155-172$. 
Miller, I. W., Epstein, N. B., Bishop, D. S., \& Keitner, G. I. (1985). The McMaster Family Assessment Device: Reliability and validity. [Print]. Iournal of Marital \& Family Therapy, 11(4), 345-356.

Moore, P. S., Whaley, S. E., \& Sigman, M. (2004). Interactions Between Mothers and Children: Impacts of Maternal and Child Anxiety. Journal of Abnormal Psychology, 113(3), 471-476.

Mun, E. Y., Fitzgerald, H. E., Von Eye, A., Puttler, L. I., \& Zucker, R. A. (2001). Temperament characteristics as predictors of externalizing and internalizing child behavior problems in the contexts of high and low parental psychopathology. Infant Mental Healih Journai, 22(3), 393-415.

Muris, P., \& Ollendick, T. H. (2005). The role of temperament in the etiology of child psychopathology. Clinical Child and Family Psychology Review, 8(4), 271-289.

Murray, L., Creswell, C., '\& Cooper, P. J. (2009). The development of anxiety disorders in childhood: An integrative review. Psychological Medicine: A Journal of Research in Psychiatry and the Allied Sciences, 39(9), 1413-1423. doi: $10.1017 / \mathrm{s} 0033291709005157$

Myers, T., A. (2011). Goodbye, Listwise Deletion: Presenting Hot Deck Imputation as an Easy and Effective Tool for Handling Missing Data. Communication Methods and Measures, 5(4), 297-310.

Nicholson, J., Sweeney, E. M., \& Geller, I. L. (1998). Mothers with mental illness: I. The competing demands of parenting and living with mental illness. Psychiatric Services, 49(5), 635-642.

Nigg, J. T. (2006). Temperament and developmental psychopathology. Journal of Child Psychology and Psychiatry, 47(3), 395-422.

Nomura, Y., Wickramaratne, P. J., Warner, V., Mufson, L., \& Weissman, M. M. (2002). Family discord, parental depression and psychopathology in offspring: Ten-year follow-up. Journal of the American Academy of Child \& Adolescent Psychiatry. 41(4), 402-409. doi: 10.1097/00004583-200204000-00012

Papp, L. M., Goeke-Morey, M. C., \& Cummings, E. M. (2004). Mothers' and fathers' psychological symptoms and marital functioning: Examination of direct and interactive links with child adjustment. Journal of Child and Family Studies, 13(4), 469-482. doi: 10.1023/B:JCFS.0000044728.34058.c0

Peleg-Popko, O., \& Dar, R. (2001). Marital quality, family patterns, and children's fears and social anxiety. Contemporary Family Therapy: An International Journal, 23(4), 465-487. doi: 10.1023/a:1013057129790

Posner, M. I., \& Rothbart, M. K. (2000). Developing mechanisms of self-regulation. Development and Psychopathology, 12(3), 427-441.

Power, T. G. (2002). Parenting Dimensions Inventory - Short Version: A Research Manual. Washington State University. Pullman. 
Rapee, R. M., Schniering, C. A., \& Hudson, J. L. (2009). Anxiety disorders during childhood and adolescence: Origins and treatment. Annual Review of Clinical Psychology(5), 311-341.

Rothbart, M. K. (1986). Longitudinal observation of infant temperament. Developmental Psychology, 22(3), 356-365.

Rothbart, M. K., Ahadi, S. A., \& Evans, D. E. (2000). Temperament and personality: Origins and outcomes. Journal of Personality and Social Psychology, 78(1), 122135.

Rothbart, M. K.. Ahadi, S. A., Hersey, K. L., \& Fisher, P. (2001). Investigations of temperament at three to seven years: The Children's Behavior Questionnaire. Child Development 72(5), 1394-1408.

Rothbart, M. K., Ellis, L. K., \& Posner, M. I. (2004). Temperament and self-regulation. In R. F. Baumeister \& K. D. Vohs (Eds.), Handbook of se!f-regulation: Research, theory, and applications. (pp. 357-370). New York, NY US: Guilford Press.

Rothbart, M. K., Posner, M. I., \& Kieras, J. (2006). Temperament, Attention, and the Development of Self-Regulation. In K. McCartney \& D. Phillips (Eds.), Blackwell handbook of early childhood development. (pp. 338-357). Malden: Blackweil Publishing.

Rothbart. M. K.. \& Putnam, S. P. (2002). Temperament and socialization. in L. Pulkkinen \& A. Caspi (Eds.), Paths to successful development: Personality in the life course. (pp. 19-45). New York, NY US: Cambridge University Press.

Rothbart, M. K., Rueda, M. R., Mayr, U., Awh, E., \& Keele, S. W. (2005). The Development of Effortful Control Deveioping individuality in the human brain: $A$ tribute to Michael I. Posner. (pp. 167-188). Washington, DC US: American Psychological Association.

Rothbart, M. K., \& Sheese, B. E. (2007). Temperament and Emotion Regulation. In J. J. Gross (Ed.), Handbook of emotion regulation. (pp. 331-350). New York, NY US: Guilford Press.

Rutter, M. (1990). Psychosocial resilience and protective mechanisms. In J. E. Rolf, A. S. Masten, D. Cicchetti, K. H. Nuechterlein \& S. Weintraub (Eds.), Risk and protecive factors in the development of psychopathology. (pp. 181-214). New York, NY US: Cambridge University Press.

Salters-Pedneault, K., Roemer, L., Tull, M. T., Rucker, L., \& Mennin, D. S. (2006). Evidence of Broad Deficits in Emotion Regulation Associated with Chronic Worry and Generalized Anxiety Disorder. Cognitive Therapy and Research, 30(4), 469-480. doi: 10.1007/s10608-006-9055-4

Schrock, M., \& Woodruff-Borden, J. (2010). Parent-child interactions in anxious families. Child \& Family Behavior Therapy, 32(4), 291-310. doi: 10.1080/07317107.2010.515523 
Simonds, J., \& Rothbart, M. K. (2004, October). The Temperament in Middle Childhood Questionnaire (TMCQ): A Computerized Self-Report Instrument for Ages 7-i 0. Paper presented at the Occasional Temperament Conference, Athens, GA.

Siqueland, L., Kendall, P. C., \& Steinberg, L. (1996). Anxiety in children: Perceived family environments and observed family interaction. [Print]. Journal of Clinical Child Psychology, 25(2), 225-237.

Southam-Gerow, M. A., \& Kendall, P. C. (2002). Emotion regulation and understanding: Implications for child psychopathology and therapy. Clinical Psychology Review, 22(2), 189-222. doi: 10.1016/s0272-7358(01)00087-3

Stark, K. D., Humphrey, L. L., Laurent, J.. Livingston, R., \& Christopher, J. (1993). Cognitive, behavioral, and family factors in the differentiation of depressive and anxiety disorders during childhood. Journal of Consulting and Clinical Psychology, 61(5), 878-886.

Steer, R. A., Kumar, G., Beck, J. S., \& Beck, A. T. (2001). Evidence for the construct validities of the Beck Youth Inventories with child psychiatric outpatients. [Print Print]. Psychological Reports, 89(3), 559-565.

Suveg, C., Zeman, J., Flannery-Schroeder, E., \& Cassano, M. (2005). Emotion Socialization in Families of Children With an Anxiety Disorder. Journal of Abnormal Child Psychology: An official publication of the International Society for Research in Child and Adolescent Psychopathology, 33(2), 145-155. doi: 10.1007/s10802-005-1823-1

Szabó, N., Deković, M., van Aken, C., Verhoeven, M., van Aken, M. A. G., \& Junger, M. (2008). The relations among child negative interactive behavior, child temperament, and maternal behavior. Early Childhood Research Quarterly, 23(3), 366-377. doi: 10.1016/j.ecresq.2008.01.004

Tan, T. X., Camras, L. A., Deng, H., Zhang, M., \& Lu, Z. (2012). Family stress, parenting styles, and behavioral adjustment in preschool-age adopted Chinese girls. Early Childhoo' Research Quarterly, 27(1), 128-136. doi: 10.1016/j.ecresq.2011.04.002

Thomas, A., \& Chess, S. (1977). Temperament and development. Oxford England: Brunner/Mazel.

Thompson, R. A. (1994). Emotion regulation: A theme in search of definition. Monographs of the Society for Research in Child Development, 59(2-3), 25-52, 250-283. doi: 1,0.2307/1166137

Turner, S. M., Beidel, D. C., \& Costello, A. (1987). Psychopathology in the offspring of anxiety disorders patients. Journal of Consuiting and Clinica! Psychoiogy, 55(2), 229-235.

Turner, S. M., Beidel, D. C., Roberson-Nay, R., \& Tervo, K. (2003). Parenting behaviors in parents with anxiety disorders. Behaviour Research and Therapy, 41(5), 541554. 
van der Bruggen, C., Stams, G., \& Bogels, S. M. (2008). Research Review: The relation between child and parent anxiety and parental control: a meta-analytic review. The Journal of Child Psychoiogy and Psychiatry, 49(12), 1257-1269.

Vasey, M. W., \& Dadds, M. R. (2001). The developmental psychopathology of anxiety. New York, NY, US: Oxford University Press.

Watson, D., \& Clark, L. A. (1984). Negative affectivity: The disposition to experience aversive emotional states. Psychological Bulletin, 96(3), 465-490.

Werner, E. (1989). Children of the Garden Island. Scientific American, 260, 106-111.

Whaley, S. E., Pinto, A., \& Sigman, M. (1999). Characterizing interactions between anxious mothers and their children. Journal of Consulting and Clinical Psychology, 67(6), 826-836.

Williams, S. R., Kertz, S. J., Schrock, M. D., \& Woodruff-Borden, J. (2012). A sequential analysis of parent-Child interactions in anxious and nonanxious families. Journal of Clinical Child and Adolescent Psychology, 41(1), 64-74. doi: 10.1080/15374416.2012.632347

Wood, J. J., McLeod, B. D., Sigman, M., Hwang, W.-C., \& Chu, B. C. (2003). Parenting and childhood anxiety: Theory, empirical findings, and future directions. [Print Electronic; Print]. Journal of Child Psychology and Psychiatry, 44(1), 134-151.

Woodruff-Borden, J., Marrow, C., Bourland, S., \& Cambron, S. (2002). The Behavior of Anxious Parents: Examining Mechanisms of Transmission of Anxiety From Parent to Child. Journal of Child and Adolescent Psychology, 31(3), 364-374.

Zahn-Waxler, C., Kochanska, G., Krupnick, J., \& McKnew, D. (1990). Patterns of guilt in children of depressed and well mothers. Developmental Psychology, 26(1), 5159. doi: $10.1037 / 0012-1649.26 .1 .51$

Zeman, J., Shipman, K., \& Suveg, C. (2002). Anger and sadness regulation: Predictions to internalizing and externalizing symptoms in children. Journal of Clinical Child and Adolescent Psychology, 31(3), 393-398. doi: 10.1207/153744202760082658 


\section{CuRriculum VitaE}

MATTHEW D. SCHROCK

McLean Hospital

Behavioral Health Partial Program

6 Willow Street

Belmont, MA 02478

617-855-4427

Belmont, MA 02478

617-955-6485

mschrock@mclean.harvard.edu

ACADEMIC HISTORY

\begin{tabular}{ll}
\hline $2012-$ Present & $\begin{array}{l}\text { McLean Hospital/Harvard Medical School } \\
\text { Postdoctoral Fellow } \\
\text { Belmont, MA }\end{array}$ \\
$2011-2012$ & $\begin{array}{l}\text { McLean Hospital/Harvard Medical School } \\
\text { Predoctoral Internship } \\
\text { Belmont, MA }\end{array}$ \\
& $\begin{array}{l}\text { University of Louisville, Louisville, KY } \\
\text { Ph.D., Clinical Psychology }\end{array}$ \\
$2007-2012$ & $\begin{array}{l}\text { University of Louisville, Louisville, KY } \\
\text { Master of Arts, Clinical Psychology }\end{array}$ \\
& City University of New York - Baruch College, New York, \\
2009 & Post Baccalaureate in Psychology \\
NY & Eckerd College, St. Petersburg, FL \\
& Bachelor of Arts in Environmental Studies
\end{tabular}

ACADEMIC APPOINTMENTS

2010-present

Clinical Fellow
Department of Psychiatry

McLean Hospital/Harvard Medical School, Belmont, MA 
CLINICAL EXPERIENCE

$2012-2013$

McLean Hospital - Behavioral Health Partial Program

Postdoctoral Fellow

Supervisors: Rima Saad, Ph.D., Thröstur Bjorgvinsson, Ph.D., and Andrew Kuller, Psy.D. Postdoctoral Fellow in partial hospital setting providing CBT oriented group and individual therapy for individuals with Axis I and Axis II disorders. Conducted multiple CBT/DBT/Psyched groups per week, and maintained 2 to 4 individual patients for shortterm intensive CBT/DBT therapy. Assisted in program development and worked with program staff to streamline and update clinical procedures. Coordinated practicum training program, and supervised training experience for four graduate level clinical psychology students.

$2011-2012$

McLean Hospital - Behavioral Health Partial Program

Predoctoral Intern

Supervisors: Rima Saad, Ph.D., John Rodolico, Ph.D., Robert Youngberg, Ph.D., and Gary Taylor, Ph.D.

Predoctoral intern in partial hospital setting providing CBT oriented group and individual therapy for individuals with Axis I and Axis II disorders. Conducted multiple

CBT/DBT/Psyched groups per week, and completed rotations in adult addictions, case management, and severe mental illness.

2010 - $2011 \quad$ University of Louisville - Psychological Services Center Clinical Graduate Teaching Assistant

Supervisor: Bernadette Walter, Ph.D.

Clinical graduate teaching assistant in department clinic setting responsible for conducting intake interviews and writing integrated reports for presentation to clinic director and treatment team. Work as teaching assistant and peer supervisor for first-year interviewing and assessment classes. Responsibilities include reviewing mock therapy sessions and providing feedback, reviewing assessment protocols such as WISC and WAIS and providing feedback on rapport building, assessment technique, and protocol scoring.

2010 - 2011 University of Louisville - University Child Health Specialist, South Graduate Student Therapist

Supervisor: Sarah Honaker, Ph.D.

Primary responsibilities include evaluation, consultation, and treatment of pediatric patients and families in a fast-paced, semi-integrated, primary care setting. Involved in treatment and case management at multiple levels including intake, treatment, and school consultation with diverse patient population. Patients range in age from 3-i 6 years and 
present with a wide range of psychological probiems including adjustment disorder, anxiety disorders, and externalizing disorders.

2009 - 2011 University of Louisville - Psychological Services Center/Geriatric Clinic Graduate Student Therapist

Supervisor: Benjamin Mast, Ph.D.

Responsibilities include administering neuropsychological testing batteries in a comprehensive primary care setting to evaluate geriatric patients for cognitive decline. Involved in comprehensive geriatric assessment (geriatric assessment team) providing neuropsychological assessment and feedback to multi-disciplinary team to determine course of treatment and provide recommendations to family and caregivers. Provide integrative treatment for clients experiencing grief/loss, caregiver burden, depression, and anxiety.

$2007-2009$

Graduate Student Therapist

University of Louisville - Psychological Services Center

Supervisor: Janet Woodruff-Borden, Ph.D.

Responsibilities include administering psychodiagnostic assessments and cognitivebehavioral treatment to individuals and families with a range of anxiety and affective disorders. Integrated report writing and peer supervision are an integral part of treatment and assessment process in department clinic setting.

$2006-2007$

Volunteer - ADHD Clinical Service

New York University - Child Study Center

Supervisor: Steven Kurtz, Ph.D., ABPP

Observed and assisted in treatment of ADHD and ODD patients with and without ADHD utilizing Parent-Child Interaction Therapy (PCIT) developed by Dr. Sheila Eyberg, worked closely with clinical staff providing skills training to patients and families; participated in two-day PCIT training seminar

$2006-2007$

Volunteer-Selective Mutism Treatment Service

Supervisor: Steven Kurtz, Ph.D., ABPP

Assisted Selective Mutism clinical staff providing novel behavioral treatment protocol developed at the Child Study Center; observed and participated as confederate in therapy sessions with clinical staff providing skills training to patients and families to help with generalization.

$2006-2007$ Volunteer - CBT/Stress Management Group

Supervisor: Lori Evans, Ph.D.

Served as co-therapist with supervising clinician providing stress and anger management skills using CBT framework for adolescents currently in psychiatric inpatient unit; assisted in the development of flexible treatment protocol to meet the highly variable demands of this transient population. 
$2009-2010$

Graduate Teaching Assistant - Research Design and Methods

University of Louisville

Supervisor: Lora Haynes, Ph.D.

Taught 50 recitation sections over course of fall and spring semesters. Responsibilities included material preparation, lectures, grading assignments, assisting students with course material, maintenance of class blackboard Web site, and recording and calculating grades.

\section{RESEARCH EXPERIENCE}

2007 - 2012 University of Louisville - Developmental Psychopathology Research Lab Graduate Student

Supervisors: Janet Woodruff-Borden, Ph.D.

My research has focused on the etiology and maintenance of anxiety within the context of the family. Recent projects include dyad-leval analysis of parent-child interactions, a path analysis model of child internalizing symptoms, a sequential analysis of parent-child interactions, and developing a model of resilience in children at risk for development of anxiety. Primary responsibilities included manuscript preparation, project design, data collection and coding, and participating in weekly lab meetings.

$2005-2007$

Research Coordinator

New York University - Child Study Center

Supervisors: Barbara Coffey, M.D., M.S. and Howard Abikoff, Ph.D.

Research coordinator for Tourettes and ADHD research institutes with responsibility for multiple NIMH and industry-sponsored studies. Responsibilities included monitoring study budgets, ensuring adherence to research protocol, helping prepare and submit progress reports, managing recruitment, maintaining IRB approval, administering selfreport measures and assessments to participants, and reporting adverse events.

PUBLICATIONS

Williams, S., Kertz, S., Schrock, M., Woodruff-Borden, J. (2012). A Sequential Analysis of Parent-Child Interactions in Anxious and Nonanxious Families. Journal of Clinical Child and Adolescent Psychology Journal of Clinical Child And Adolescent Psychology, 41(1), 64-74. doi:10.1080/15374416.2012.632347

Schrock, M., Woodruff-Borden, J. (2010). Parent-child Interactions in Anxious Families. Child and Family Behavior Therapy, 32 (4), 291-310.

Doi:10.1080/07317107.2010.515523

Crawford, C., Schrock, M., Woodruff-Borden, J. (2010). Child Internalizing Symptoms: Contributions of Child Temperament, Maternal Negative Affect, and Family Functioning. Child Psychiatry and Human Development, 42(1), 53-64. doi:10.1007/s10578-010-0202-5 
Budman, C., Coffey, B., Shechter, R., Schrock, M., Wieland, N., Spirgel, A., et al. (2008). Aripiprazole in children and adolescents with Tourette disorder with and without explosive outbursts. Journal of Child and Adolescent Psychopharmacology, 18(5), 509-515. doi:10.1089/cap.2007.061.

\section{PRESENTATIONS}

Schrock, M., Hosey, R., Williams, S., Woodruff-Borden, J. (2010, November). Child Internalizing Symptoms: The Roie of Child Temperament, Maternal Anxiety, and Familv Environment. Poster presented to the $45^{\text {th }}$ annual meeting of the Association for Behavioral and Cognitive Therapies, Toronto, Canada.

Hosey, R., Schrock, M., Williams, S., Woodruff-Borden, J. (2010, November). The Role of Child and Parent Factors in Parent Behavioral Negativity: A Path Analysis. Poster presented to the $45^{\text {th }}$ annual meeting of the Association for Behavioral and Cognitive Therapies, Toronto, Canada.

Schrock, M., Kertz, S., Williams, S., Hosey, R., Woodruff-Borden, I. (2010, November). The Impact of Stressful Life Events on Anxious and Non-anxious Parents' Conditional Responses to Child Behavior. Poster presented to the $44^{\text {th }}$ annual meeting of the Association for Behavioral and Cognitive Therapies, San Francisco, CA.

Hosey, R., Schrock, M., Williams, S., Kertz, S., Woodruff-Borden, J. (2010, November). Maternal anxiety moderates the relationship between child emotion word use and maternai sensitivity. Poster presented to the $44^{\text {th }}$ annual meeting of the Association for Behavioral and Cognitive Therapies, San Francisco, CA.

Kertz, S., Hosey, R., Schrock, M., Williams, S., Wood־uff-Borden, J. (2010, November). Child Coping Style Moderates the Relationship Between Trait Anxiety and Anxiety Symptoms. Poster submitied to the $44^{\text {th }}$ annual meeting of the Association for Behavioral and Cognitive Therapies, San Francisco, CA.

Williams, S., Kertz, S., Hosey, R., Schrock, M., Woodruff-Borden, J. (2010, November). The Roie of Anxiety on Parent Coaching and Dismissing Behaviors and Their Relationship to Child Anxiety. Poster submitted to the $44^{\text {th }}$ annual meeting of the Association for Behavioral and Cognitive Therapies, San Francisco, CA

Schrock, M., Kertz, S., Williams, S., Woodruff-Bcrden, J. (2009, November) Anxious and Non-Anxious Children's Response to Parental Aversiveness: A Sequential Analysis. Poster presented at the $43^{\text {rd }}$ annual meeting of the Association for Behavioral and Cognitive Therapies, New York, NY.

Kertz, S., Schrock, M., Williams, S., Woodruff-Borden, J. (2009, November). A Sequential Analysis of the Influence of Parent and Child Anxiety on Child Responses 
to Parental Aversiveness. Foster presented at the $43^{\text {rd }}$ annual meeting of the Association for Behavioral and Cognitive Therapies, New York, NY.

Williams, S., Kertz, S., Schrock, M., Woodruff-Borden, J. (2009, November). Parental Behaviors Following Child Negativity in Anxious and Non-Anxious Parents: A Sequential Analysis. Poster presented at the $43^{\text {rd }}$ annual meeting of the Association for Behavioral and Cognitive Therapies, New York, NY.

Hosey, R., Schwarz, R., Schrock, M., Kertz, S., Williams, S., Briggs, N, WoodruffBorden, I. (2009, November). Language Use as a Characteristic of Anxiety in ParentChild Interactions. Poster presented at the $43^{\text {rd }}$ annual meeting of the Association for Behavioral and Cognitive Therapies, New York, NY.

Schrock, M., Hosey, R., Kertz, S., Williams, S., Woodruff-Borden, J. (2008, November). Impact of Parental Anxiety on Parent's Perceptions of Child Behavior. Poster presented at the $42^{\text {rd }}$ annual meeting of the Association for Behavioral and Cognitive Therapies, Orlando, FL.

Crawford, C., Schrock, M., Woodruff-Borden, J. (2008, November). Childhood Internalizing Disorders: Using Negative Affect and Family Functioning to Predict Internalizing Symptoms in Children 3-5 Years. Poster presented at the $42^{\text {rd }}$ annual meeting of the Association for Behavioral and Cognitive Therapies, Orlando, FL.

Hosey, R., Schrock, M., Kertz, S, Williams, S., Chapman, L.K., Woodruff-Borden, J., Newton, T. (2008, November). Anxiety as a Function of Crime Risk in a Primary Care Sample. Poster presented at the $42^{\text {rd }}$ annuai meeting of the Association for Behavioral and Cognitive Therapies, Orlando, FL.

Kertz, S., Hosey, R., Schrock, M., Williams, S., Woodruff-Borden, J. (2008, November). A Path Analysis of Parent and Child Behaviors: Differences in Children with GAD and Other Anxiety Disorders. Poster presented at the $42^{\text {rd }}$ annual meeting of the Association for Behavioral and Cognitive Therapies, Orlando, FL.

Schrock, M., Kertz, S., Woodruff-Borden, J.. Chapman, L. K. (2008, May). Reciprocal patterns of interaction in anxious families. Poster presented at the $20^{\text {th }}$ annual meeting of the Association for Psychological Science, Chicago, IL.

Gabbay, V., Hess, D., Alonso, C., Schrock, M., Goner, O. (2005, October). Proton Spectroscopy Study of the Striatum in Adolescent Depression. Presented at the International Society for Magnetic Resonance in Medicine (ISMRM) meeting on MR Spectroscopy in Neuropsychiatric Disorders, Alberta, Canada.

Coffey, B., Gabbay, V., Meyer, L., Wachtel, C., Anam, S., Babb, J., Rabinovitz, B., Shechter, R., Schrock, M., Wielaná, N. (2006, October). PANDAS: Review of Diagnosis \& Treatment in a Large Metropolitan Area. Presented at the $53^{\text {rd }}$ annual 
meeting of the American Academy of Child and Adolescent Psychiatry, San Diego, CA.

MEMBERSHIPS

2004-2012

2004-2012

2011

Association of Behavior and Cognitive Therapies (ABCT) American Psychological Association - Graduate Affiliate Gerontological Society of America 